\title{
Hepatic Overexpression of Hemopexin Inhibits Inflammation and Vascular Stasis in Murine Models of Sickle Cell Disease
}

\author{
Gregory M Vercellotti, ${ }^{1,2}$ Ping Zhang, ${ }^{1,2}$ Julia Nguyen, ${ }^{1,2}$ Fuad Abdulla, ${ }^{1,2}$ Chunsheng Chen, ${ }^{1,2}$ \\ Phong Nguyen, ${ }^{1,2}$ Carlos Nowotny, ${ }_{1,2}$ Clifford J Steer, ${ }^{3}$ Ann Smith, and John D Belcher ${ }^{1,2}$
}

${ }^{1}$ Division of Hematology, Oncology and Transplantation, Department of Medicine, University of Minnesota, Minneapolis, Minnesota, United States of America; ${ }^{2}$ Vascular Biology Center, University of Minnesota, Minneapolis, Minnesota, United States of America; ${ }^{3}$ Division of Gastroenterology, Department of Medicine, and Department of Genetics, Cell Biology and Development, University of Minnesota, Minneapolis, Minnesota,United States of America; and ${ }^{4}$ Division of Molecular Biology and Biochemistry, School of Biological Sciences, University of Missouri-Kansas City, Kansas City, Missouri, United States of America

\begin{abstract}
Sickle cell disease (SCD) patients have low serum hemopexin (Hpx) levels due to chronic hemolysis. We hypothesized that in SCD mice, hepatic overexpression of hemopexin would scavenge the proximal mediator of vascular activation, heme, and inhibit inflammation and microvascular stasis. To examine the protective role of Hpx in SCD, we transplanted bone marrow from NY1DD SCD mice into $\mathrm{Hpx}^{-/-}$or $\mathrm{Hpx}^{+/+} \mathrm{C} 57 \mathrm{BL} / 6$ mice. Dorsal skin fold chambers were implanted 13 wks post-transplant, and microvascular stasis (\% nonflowing venules) was evaluated in response to heme infusion. $\mathrm{Hpx}^{-1 /}$ sickle mice had significantly greater microvascular stasis in response to heme infusion than $\mathrm{Hpx}^{+/+}$sickle mice $(p<0.05)$, demonstrating the protective effect of Hpx in SCD. We utilized Sleeping Beauty (SB) transposon-mediated gene transfer to overexpress wild-type rat Hpx (Wt-Hpx) in NY1DD and Townes-SS SCD mice. Control SCD mice were treated with lactated Ringer's solution (LRS) or a luciferase (LuC) plasmid. Plasma and hepatic Hpx were significantly increased compared with LRS and Luc controls. Microvascular stasis in response to heme infusion in NY1DD and Townes-SS mice overexpressing wt-Hpx had significantly less stasis than controls $(p<0.05)$. Wt-Hpx overexpression markedly increased hepatic nuclear Nrf2 expression, $\mathrm{HO}-1$ activity and protein, and the heme-Hpx binding protein and scavenger receptor CD91/LRP1, and decreased NF-kB activation. Two missense (ms)-Hpx SB constructs that bound neither heme nor the Hpx receptor CD91/LRP1 did not prevent heme-induced stasis. In conclusion, increasing Hpx levels in transgenic sickle mice via gene transfer activates the $\mathrm{Nrf} 2 / \mathrm{HO}-1$ antioxidant axis and ameliorates inflammation and vasoocclusion.
\end{abstract}

Online address: http://www.molmed.org

doi: $10.2119 / \mathrm{molmed} .2016 .00063$

\section{INTRODUCTION}

Sickle cell disease (SCD) is an unrelenting hemolytic disease caused by a single base pair mutation in the $\beta$-globin chain of hemoglobin. SCD is characterized by recurring episodes of painful vasoocclusion, leading to ischemia-reperfusion injury and organ damage. Polymerization of hemoglobin-S in the deoxy conformation shortens the lifespan of sickle erythrocytes and promotes intravascular and extravascular hemolysis. When erythrocytes are lysed, extracellular hemoglobin is released into plasma and easily oxidized from ferrous $\left(\mathrm{Fe}^{2+}\right)$ to ferric $\left(\mathrm{Fe}^{3+}\right)$ hemoglobin (methemoglobin), from which heme readily dissociates into the vasculature (1-3). Furthermore, plasma red cell microparticles are increased and laden with heme in SCD patients (4).

Address correspondence to Gregory M Vercellotti, MD, University of Minnesota, 420 Delaware Street SE, MMC 480, Minneapolis, MN 55455, USA. Phone: 612-626-3757;

Fax: 612-626-3757; E-mail: verce001@umn.edu.

Submitted March 11, 2016; Accepted for Publication July 11, 2016; Published Online (www.molmed.org) July 19, 2016.

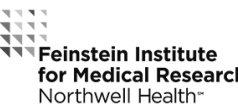

Feinstein Institute Northwell Health

Heme is a potent inducer of vascular inflammation (2,5-8). Heme derived from sickle red blood cells (RBCs) acts as a damage-associated molecular pattern (DAMP) that can activate toll-like receptor 4 (TLR4) of the innate immune system, independent of its cognate ligand lipopolysaccharide (LPS) (9), leading to oxidant production, inflammation, vaso-occlusion (VO) ischemia and tissue injury, including acute chest syndrome $(2,4,10)$. In SCD mice, the combination of heme-induced oxidative stress, inflammation and adhesion of circulating blood cells to vascular endothelium is a key driver of the proinflammatory and prothrombogenic vasculature that promotes sludging and stasis of blood flow in the postcapillary venules (11-17). Cells defend or adapt to heme-mediated 
oxidative stress by inducing heme oxygenase-1 (HO-1) and heavy chain ferritin (18-22). Haptoglobin and Hpx sequester plasma hemoglobin and heme, respectively, transporting them efficiently to macrophages and hepatocytes, respectively, for catabolism and detoxification of the heme via induction of HO-1 (23-26). Nearly 50 years ago, Muller-Eberhard showed that SCD patients have subnormal plasma concentrations of both haptoglobin and Hpx as well as increased heme-albumin (27). Over the past 10 years, numerous studies have shown in animal models that supplementation with haptoglobin or Hpx can prevent organ toxicity due to plasma hemoglobin or heme (28-34). Conversely, Hpx gene null mice $\left(\mathrm{Hpx}^{-/-}\right)$ are especially prone to oxidative stress and inflammation $(32,35)$.

Thus, several lines of evidence support Hpx playing a vital role in the inhibition of inflammation and vasoocclusion in sickle mice. In this study we treated the NY1DD and Townes-SS sickle mouse models with Hpx gene transfer targeted to the liver and evaluated the effects on cytoprotective pathways and $\mathrm{Hb}$ - and heme-induced vasoocclusion in a dorsal skin-fold chamber (DSFC) model. Our results suggest that hepatic overexpression of Hpx in sickle mice inhibits inflammation and microvascular stasis in the DSFC model by delivering heme to CD91/LRP1 on the liver and increasing nuclear Nrf2 activation and HO-1 expression in the liver $(24,36,37)$.

\section{MATERIALS AND METHODS}

\section{Heme}

The term "heme" is used generically to refer to both heme and hemin. These studies used hematin that was prepared immediately before use by mixing $10 \mathrm{mg}$ hemin chloride (Frontier Scientific, 98.6\% purity), $10 \mathrm{mg}$ D-sorbitol (Sigma-

Aldrich) and $6.9 \mathrm{mg}$ sodium carbonate (Sigma-Aldrich) in $5.7 \mathrm{~mL}$ sterile saline (Baxter) for $30 \mathrm{~min}$ in the dark. All heme preparations, appropriately diluted in saline, were filtered at $0.22 \mu \mathrm{m}$.
Mice

All animal experiments were approved by the University of Minnesota's Institutional Animal Care and Use Committee. These studies utilized male and female NY1DD (38) and HbSS-Townes (39) transgenic sickle mice, ages 8-20 wks, with weights between $20 \mathrm{~g}$ and $30 \mathrm{~g}$, housed in SPF cages on a $12 \mathrm{~h}$ light/ dark cycle at $21^{\circ} \mathrm{C}$. Hydrodynamic infusions for the gene transfer studies used NY1DD and HbSS-Townes mice 8-12 wks of age. All animals were monitored daily, including weekends and holidays, for health problems, food and water levels, and cage conditions. The NY1DD and Townes-SS mice were generated from C57BL/ 6 and 129/B6 genetic backgrounds, respectively. The NY1DD mice were homozygous for deletion of the mouse $\beta^{\text {major }}$ globin and expressed a human $\alpha$ and $\beta^{S}$ globin transgene. The Townes-SS mice were created by knocking human $\alpha$ and ${ }^{\mathrm{A}} \gamma \beta^{\mathrm{S}}$ globins into the deletion sites for murine $\alpha$ and $\beta$ globins. Townes-SS mice have severe anemia and an RBC half-life of $2.5 \mathrm{~d}$ (40). NY1DD mice were used for most of these studies, and Townes-SS mice were used to confirm hepatic and plasma Hpx expression and the effects of Hpx on stasis. The $\mathrm{Hpx}^{-/-}$mice were a generous gift from Dr. Raymond Regan at Thomas Jefferson University, Philadelphia,

Pennsylvania (41).

\section{Bone Marrow Transplants}

Chimeric mice were generated by harvesting sickle bone marrow (BM) from NY1DD mice $\left(\beta^{\mathrm{S+/+}}\right)$ and transplanting the BM into lethally irradiated $H p x^{-/-}$or $\mathrm{Hpx}^{+/+}$C57BL/ 6 non-sickle mice. Recipients (8-10 wks of age) were irradiated with two doses of 5 Gy (X-RAD 320 Biological Irradiator) $3 \mathrm{~h}$ apart. During the $3 \mathrm{~h}$ interval, BM donors were euthanized and BM was collected from both femurs. Ten million BM cells were injected via tail vein into each irradiated recipient. Drinking water containing $0.2 \%$ neomycin sulfate (Sigma-Aldrich) was given to transplanted mice for $3 \mathrm{wks}$ immediately after transplantation. Twelve weeks post-transplant, globin phenotype was determined by $\mathrm{Hb}$ isoelectric focusing. Chimeric mice were implanted with a DSFC 12-14 wks after transplant.

\section{Plasmids}

Plasmid pT2/CAGGS-Luc containing a T2 $S B$ transposon encoding firefly luciferase downstream of a CAGGS promoter (42), and plasmid pKCMV-SB100X encoding hyperactive SB100X transposase (43), were a gift from Dr. Scott McIvor (University of Minnesota). The transposon plasmid containing wild-type (wt) rat $H p x$ (wt-Hpx) pT2/CAGGS-wt-Hpx was constructed by removing Luc from pT2/CAGGS-Luc via NotI and ClaI digestion and ligating the resulting vector with the coding region of rat Hpx cDNA, which was amplified from pExpress-rat Hpx using primers with NotI and ClaI sites on the $5^{\prime}$ and $3^{\prime}$ end, respectively. The Hpx His sites coordinating heme iron (H149, $\mathrm{H} 235$ and $\mathrm{H} 291$ in rat Hpx) and the core (Arg-Gly-Glu) of JEN14 epitope recognized by Hpx-heme receptor as defined previously (44) were chosen to make Hpx mutants. The transposon plasmids containing missense (ms) rat Hpx-heme binding mutant $\mathrm{H} 149 \mathrm{~A} / \mathrm{H} 235 \mathrm{~A} / \mathrm{H} 291$ (ms-Hpx ${ }_{\mathrm{HM}}$ ) pT2/CAGGS-ms-Hpx ${ }_{\mathrm{HM}}$ and ms-Hpxreceptor-binding mutant R150A/E152A $\left(\mathrm{ms}^{-} \mathrm{Hpx}_{\mathrm{RM}}\right) \mathrm{pT}$ /CAGGS-ms-Hpx $\mathrm{RM}$ were generated using QuickChange II XLSite-Directed Mutagenesis kit (Agilent Technologies). To facilitate purification of the recombinant rat $\mathrm{Hpx}$ in mammalian cell culture, Flag tag was added to the $\mathrm{C}$ terminal of rat $\mathrm{Hpx}$ in pT2/CAGGS-wt-Hpx, pT2/CAGGS$\mathrm{ms}^{-\mathrm{Hpx}_{\mathrm{HM}}}$ and pT2/CAGGS-ms-Hpx $\mathrm{RM}_{\mathrm{RM}}$ using a $3^{\prime}$ primer containing the coding sequence of Flag (DYKDDDDK): 5'TGACTTGCGGCCGCTCATTACT TGTCGTCATCGTCTTTGTAGTCAC CTCCTTGACTGCAGCCAAG3'. The sequences of the constructed plasmids were confirmed by Sanger sequencing in the University of Minnesota Genomic Center. 


\section{Transgene Delivery to Sickle Mice}

The hydrodynamic delivery procedure for the SB transposon system allows efficient delivery of transposons to the livers of mice (45). The procedure involves rapid, high-pressure injection of a DNA solution into the tail vein. A wt-Hpx plasmid (pT2/CAGGS-Hpx) or ms-Hpx plasmids (pT2/CAGGS-ms-Hpx $\mathrm{HM}_{\mathrm{HM}}$ or pT2/CAGGS-ms-Hpx ${ }_{\text {RM }}$ ) were delivered with an SB100X transposase plasmid (pK/CMV-SB100X) and Luc plasmid (pT2/CAGGS-Luc, as tracer) in trans into NY1DD or Townes-SS SCD mice by hydrodynamic tail vein injections of plasmid DNA (10\% body weight, up to $2.5 \mathrm{~mL}$ ) in sterile LRS (45). Control SCD mice were infused with the same volume of LRS alone or the Luc plasmid with SB100X transposase plasmid in trans.

\section{Bioluminescence Imaging In Vivo}

Expression of Luc in living mice was monitored one week after hydrodynamic infusions by bioluminescence imaging, using Xenogen's IVIS Imaging System with Living Imaging program, as previously described (45). Briefly, mice were anesthetized with isoflurane mixed with pure oxygen, and $0.1 \mathrm{ml}$ of D-luciferin $(28.5 \mathrm{mg} / \mathrm{mL}$, Promega) was injected intraperitoneally. Five minutes after injection of the luciferin substrate, mice were imaged according to the manufacturer's instructions. Luc expression determined by the bioluminescence imaging is expressed as photons emitted per second per square centimeter.

\section{Western Blots}

Microsomes and nuclear extracts were isolated as previously described from the mouse (46). Blots of cellular subfractions were immunostained with primary antibodies to Hpx (BioVision \#3899-200 or Abcam ab 150401), Nrf2 (Cell Signaling \#8882), HO-1 (Enzo \#ADI-OSA-111), phospho (Ser536, Cell Signaling \#3031) and total (Cell Signaling \#3034) NF-KB p65, CD91/LRP1 (Abcam \#ab92544).

Primary antibodies were labeled with secondary antibodies conjugated to alkaline phosphatase (Santa Cruz, \#SC-2007) and visualized with ECF ${ }^{\mathrm{TM}}$ substrate (GE
Healthcare) and a Storm ${ }^{\mathrm{TM}}$ Reader (GE Healthcare). Plasma samples were run on SDS-PAGE for western blots using $1 \mu \mathrm{L}$ of each plasma sample per lane. The blots were immunostained for Hpx (BioVision, \#3899-200). The primary antibodies were visualized as described above. Immunoreactive bands on images were quantitated using ImageJ software (NIH). Enrichment of bands was measured by calculating the ratios of sickle mice to C57BL/ 6 or Townes-AA mice.

\section{Expression and Purification of C-Flag-tagged Recombinant Rat wt-Hpx, Heme-binding Mutant $\left(\mathrm{ms}-\mathrm{Hpx}_{\mathrm{HM}}\right)$ and Receptor-binding Mutant (ms-Hpx $\mathrm{RM}$ )}

Expression plasmids pT2/CAGGS-wtHpx-Flag, pT2/CAGGS-ms-Hpx ${ }_{\mathrm{HM}}$-Flag and pT2/CAGGS-ms-Hpx $\mathrm{RM}$-Flag were used to produce wt-Hpx-Flag, $\mathrm{Hpx}_{\mathrm{HM}^{-}}$ Flag and ms-Hpx ${ }_{\mathrm{RM}}$-Flag, respectively, in Chinese hamster ovary $(\mathrm{CHO})$ cells, as described previously $(47,48)$. $\mathrm{CHO}$ cells were maintained in RPMI-1640 with L-glutamine (Gibco) supplemented with $10 \%$ fetal bovine serum in $5 \% \mathrm{CO}_{2}$ at $37^{\circ} \mathrm{C}$. Cells in T225 $\mathrm{cm}^{2}$ culture flask with RPMI-1640 free of serum were transiently transfected with polyethylenimine (PEI, linear, MW 2,500) (Polysciences) using a 3:1 ratio of PEI to DNA $(\mathrm{w} / \mathrm{w})$. After $18 \mathrm{~h}$ of incubation, the cells were changed to protein-free media ProCHO-AT (Lonza). Four days post-incubation of CHO cells in ProCHO-AT, the conditioned media was collected, and cleared by centrifugation at $600 \times \mathrm{g}$ for 30 $\mathrm{m}$ at $4^{\circ} \mathrm{C}$ and filtration using a $0.22 \mu \mathrm{m}$ stercup vacuum filter apparatus (Corning). Subsequently, the recombinant $\mathrm{Hpx}$ Flag in the cleared conditioned medium was purified by anti-Flag M2 affinity gel (Sigma-Aldrich) column chromatography following the manufacturer's instructions. The bound Flag fusion protein was eluted by competition with Flag peptide, and further concentrated using a 30k centrifugal filter unit (Amicon). The purity and concentration of the protein was determined by a $4-15 \%$ SDS-PAGE and Coomassie R-250 stain (Bio-Rad), with a BSA standard 1-10 $\mu$ g loaded in the same gel to estimate its concentration by comparing the band intensities. The recombinant wt-Hpx and the ms mutants were confirmed by western blots with a primary antibody against wt-Hpx (Abcam \#ab150401).

\section{Heme-binding Assay}

A standard Hpx-heme-binding assay as described previously (49) was performed to determine heme-binding activity of the recombinant Hpx proteins wt-Hpx-Flag, ms-Hpx $\mathrm{HM}^{-}$-Flag and ms-Hpx ${ }_{\mathrm{RM}}-\mathrm{Flag}$, by UV/Vis absorption spectrometry (250-600 nm) using Nanophotometer P330 (Implen) with an optical path length of $10 \mathrm{~mm}$. Rat serum Hpx (Athens Research and Technology) was used as a positive control.

\section{CD91/LRP1 Receptor Binding}

HepG2 human hepatocytes were cultured to confluence on glass-bottom 24-well plates coated with rat tail collagen type I in $10 \%$ FBS growth media. Cells were incubated in 1\% FBS media with wt-Hpx-Flag, ms-Hpx $\mathrm{HM}^{-}$-Flag, or $\mathrm{ms}^{-H p x_{\mathrm{RM}}}$-Flag $(1 \mu \mathrm{M})$ with or without hemin $(1 \mu \mathrm{M})$ for $1 \mathrm{~h}$. To assess specific binding of Hpx-Flag (wt or ms) to CD91/LRP1, HepG2 cells were treated with a 20-fold excess of purified human Hpx $(20 \mu \mathrm{M})+$ Hpx-Flag (wt or ms) + hemin $(1 \mu \mathrm{M})$. Post-incubation, cells were fixed with cold $4 \%$ paraformaldehyde for $5 \mathrm{~m}$. Fixed cells were incubated with mouse anti-Flag IgG (Sigma-

Aldrich, \# F1804) and rabbit anti-human CD91/LRP1 (Abcam, \#ab92544) to assess co-localization of Hpx-Flag (wt or ms) and CD91/LRP1. Primary antibodies to Flag and CD91/LRP1 were visualized with $\mathrm{Cy} 3$ anti-mouse and FITC antirabbit secondary antibodies, respectively (Jackson Immunoresearch, \#715-165-150 and \#711-095-152), followed by nuclear DAPI stain (Life Technologies, \#D1306). All photo images were taken at $100 \times$ with Nikon A1Rsi confocal w/SIM Super Resolution microscope and processed with NIS/element version 4.40 and Adobe Photoshop. 


\section{Quantitative RT-PCR}

Total RNA was extracted from tissues ( $30 \mathrm{mg}$ ) using RNeasy Mini kit (Qiagen). RNA was digested with RNase-free DNase I (Roche) to remove any contaminating DNA, and the DNase I was heat-inactivated by incubation at $75^{\circ} \mathrm{C}$ for $10 \mathrm{~m}$. cDNA was generated from 500 ng RNA using qScript cDNA Supermix (Quanta BioSciences). qPCR for mouse and rat Hpx mRNA was measured in triplicate once or twice on a LightCycler 480 (Roche) using FastStart Universal SYBR Green Master (Roche).

The mouse and rat primers were verified to be specific for mouse and rat Hpx. The primer sequences were as follows: rat Hpx forward primer 5'CAAG CCAGACTCAGATGTAATCG3', rat Hpx reverse primer 5'GGGA TTCTTCCACCTCTCTGA3', mouse $\mathrm{Hpx}$ forward primer $5^{\prime} \mathrm{CA}$ GCAGTGGCGCTAAATATCC3', mouse Hpx reverse primer 5' ACTCTCCCGTTGGCAGTAGG3'.

\section{Plasma Hemoglobin and Heme}

Plasma hemoglobin was measured spectrophotometrically by the Fairbanks AII method (50). Total plasma heme levels were measured colorimetrically at 400 nm using a QuantiChrom ${ }^{\mathrm{TM}}$ Heme Assay Kit (BioAssay Systems). This method measures total plasma heme.

\section{Measurement of HO Enzyme Activity in Liver Microsomes}

Heme oxygenase (HO) activity was measured as previously described (20) in freshly isolated liver microsomes sonicated once for $10 \mathrm{~s}$. Microsomes ( $2 \mathrm{mg}$ ) in $2 \mathrm{mM} \mathrm{MgCl}, 0.1 \mathrm{M} \mathrm{K}_{2} \mathrm{HPO}_{4}$ buffer, pH 7.4 were added to the reaction mixture $(400 \mu \mathrm{L}$, final) containing $2.5 \mu \mathrm{g}$ recombinant biliverdin reductase (Assay Designs), 2 mM glucose-6phosphate, 0.2 U glucose-6-phosphate dehydrogenase, $50 \mu \mathrm{M}$ hemin chloride and $0.8 \mathrm{mM}$ NADPH (Calbiochem) for $1 \mathrm{~h}$ in the dark. Bilirubin that was formed was extracted into chloroform and measured by the delta OD at $464-530 \mathrm{~nm}$ (extinction coefficient,
$40 \mathrm{mM}^{-1} \mathrm{~cm}^{-1}$ for bilirubin). HO activity is expressed as pmol of bilirubin formed/mg microsomal protein/h.

\section{Measurement of Vasoocclusion (Stasis) and Tissue Collection}

Sickle mice were implanted with DSFCs as previously described (51). Three days later, these mice with were anesthetized with a mixture of ketamine (106 mg/kg) and xylaxine (7.2 mg/kg) and placed on a special intravital microscopy stage, and 20-25 flowing subcutaneous venules in the DSFC window were selected and mapped. After baseline selection of flowing venules, mice were challenged with hemin $(1.6 \mu$ mols $/ \mathrm{kg}$, i.v.) via the tail (2). The same vessels that were selected and mapped at baseline were reexamined for stasis (no flow) at $1 \mathrm{~h}$ and $4 \mathrm{~h}$ after hemin infusion. Percentage of stasis was calculated at each time point. After the $4 \mathrm{~h}$ stasis measurement, the mice were euthanized in a $\mathrm{CO}_{2}$ chamber. Heparinized blood was collected from the heart and placed on ice for collection of plasma, livers were flash-frozen in liquid $\mathrm{N}_{2}$ and all samples were stored at $-85^{\circ} \mathrm{C}$.
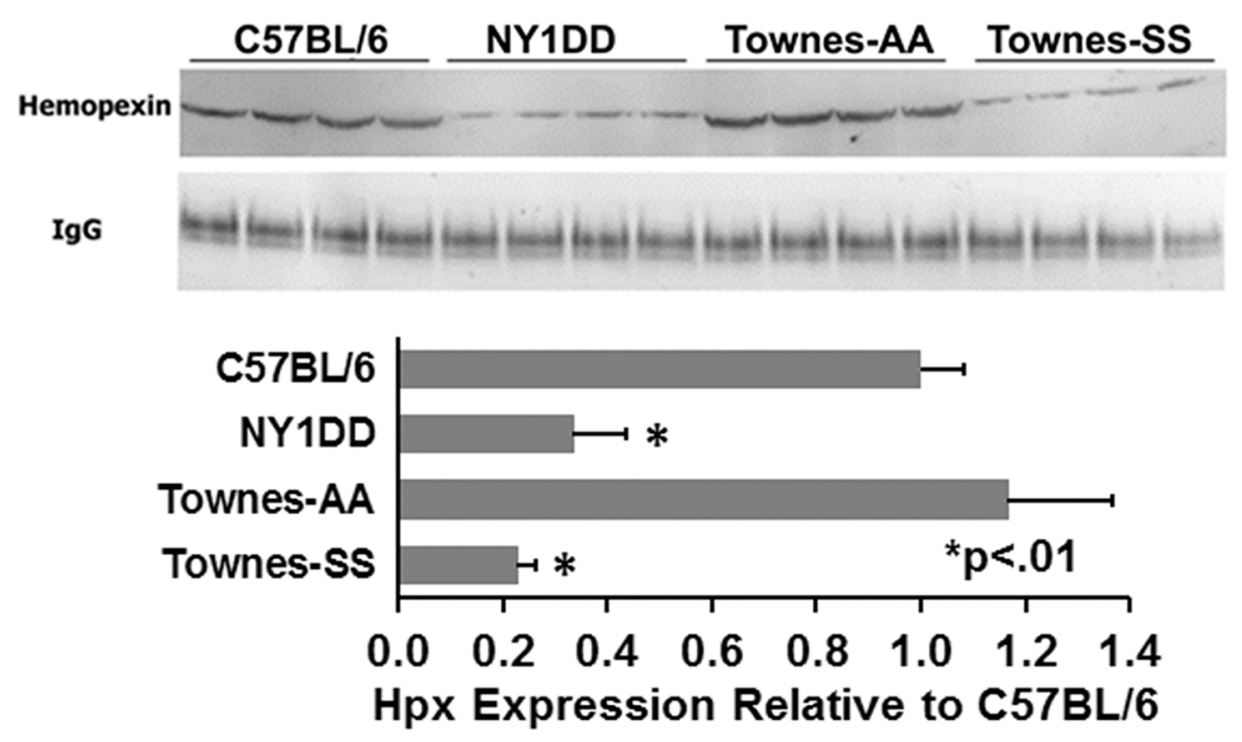

Figure 1. Plasma hemopexin is decreased in sickle mice. Plasma was collected from the abdominal aortae of C57BL/6, NY1DD, Townes-AA and Townes-SS mice ( $n=4 /$ group). Plasma ( $1 \mu \mathrm{L}$ ) was run on western blots and immunostained for murine hemopexin ( $68 \mathrm{kDa}$ ) or lgG (155 kDa). Bar graph represents relative hemopexin band intensities (mean $+\mathrm{SD}$ ) relative to C57BL/6. ${ }^{*} p<0.01$ NY1DD versus C57BL/ 6 and Townes-SS versus Townes-AA. 
methemalbumin (52). Albumin has 70-fold greater molarity in plasma relative to Hpx, and some have suggested that albumin may protect the vasculature against free heme toxicity. Yet, we and others have shown that Hpx supplementation in Hpx-deficient sickle mice, which have a large molar excess of albumin, can blunt toxicity due to free heme (2). To test whether Hpx is indeed protective in SCD against heme toxicity, we transplanted NY1DD BM into $\mathrm{Hpx}^{+/+}$ or $\mathrm{Hpx}^{-/-} \mathrm{C} 57 \mathrm{BL} / 6$ mice. After 12 wks, hemoglobin electrophoresis confirmed hemoglobin $S$ in the transplanted mice (data not shown) and a DSFC was implanted for assessment of microvascular stasis. As expected, there was no detectable plasma Hpx in the $\mathrm{Hpx}^{-/-}$sickle mice (Figure 2A), while there was detectable Hpx in the $\mathrm{Hpx}^{+/+}$sickle mice, suggesting that these mice, despite having sickle red cells, were not briskly hemolyzing post-transplant. $\mathrm{Hpx}^{-/-}$sickle mice were more sensitive to the pathological effects of infused heme $(3.2 \mu \mathrm{mol} / \mathrm{kg})$, developing $33 \pm 3 \%$ static vessels at $1 \mathrm{~h}$ compared with $21 \pm 5 \%$ in $\mathrm{Hpx}^{+/+}$sickle mice $(p<0.025$, Figure $2 \mathrm{~B})$.

To further investigate the protective role of Hpx in SCD, we utilized gene transfer to augment Hpx production in SCD mice. We hydrodynamically infused SB100X transposase (SB100X) driven by a robust CMV promoter in trans with a rat wt-Hpx transposon driven by a constitutive CAGGS promoter into the tail veins of NY1DD and Townes-SS sickle mice. A Luc transposon or equal volume of LRS was infused as control for the hydrodynamic infusion. One week after hydrodynamic infusion, Luc gene expression was predominantly localized to the liver, as determined by whole-body imaging of Luc activity (Supplemental Figure 1). Four weeks after hydrodynamic infusion, there was a marked increase in Hpx levels in the livers (Figures 3A and B) and plasma (Figures 3C-F) of wt-Hpx-treated mice, but not the Luc- or LRS-treated mice. The relative Hpx levels in the plasma of NY1DD mice receiving wt-Hpx was almost double the plasma

NY1DD BM
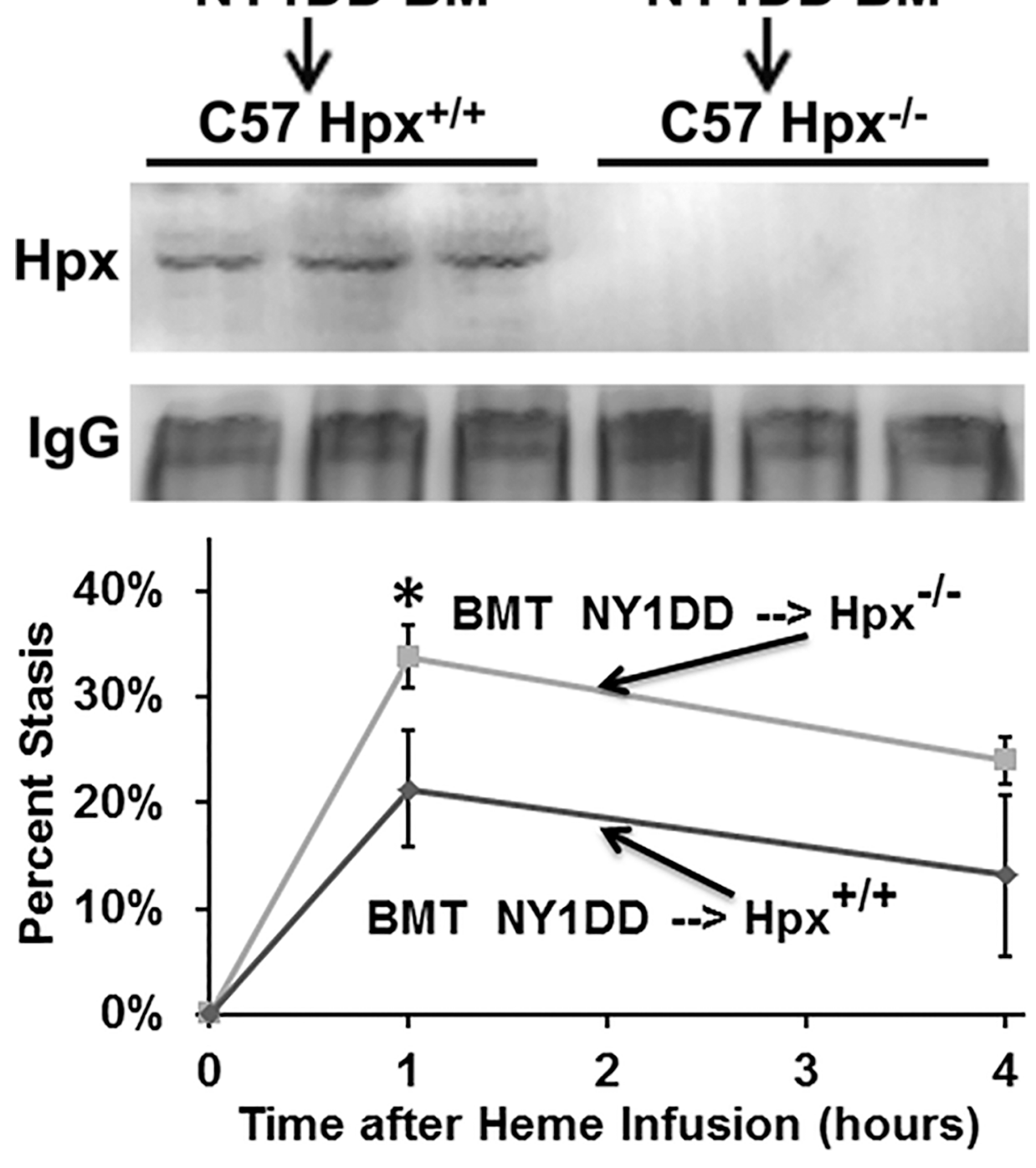

Figure 2. $\mathrm{Hpx}^{-/-}$sickle mice develop more stasis than $\mathrm{Hpx}^{+/+}$sickle mice following heme infusion. NY1DD bone marrow (BM) was transplanted into C57BL/6 $\mathrm{Hpx}^{+/+}$and C57BL/6 $\mathrm{Hpx}^{-1-}$ mice $(n=3)$. Twelve weeks after BM transplant (BMT), plasma Hpx levels were examined on western blot (A) and microvascular stasis was measured in a DSFC at $1 \mathrm{~h}$ and $4 \mathrm{~h}$ after infusion of $3.2 \mu \mathrm{mols} / \mathrm{kg}$ of heme (B). Percentage of stasis (mean $\pm \mathrm{SD}$ ) was calculated at $1 \mathrm{~h}$ and $4 \mathrm{~h}$ after heme infusion. ${ }^{*} \mathrm{P}<0.025 \mathrm{NY} 1 \mathrm{DD} \mathrm{Hpx}^{+/+}$versus NY1DD Hpx ${ }^{-1}$.

Hpx levels in untreated C57BL/6 mice $(\mathrm{D}, p<0.01)$. The relative Hpx levels in the plasma of Townes-SS mice receiving wt-Hpx was approximately $70 \%$ of the plasma Hpx levels in untreated Townes-AA mice (F), although the relative Hpx levels were not significantly different between Townes-SS-wt-Hpx and untreated Townes-AA mice. The relative Hpx levels in the plasma of TownesSS-LRS and Townes-SS-Luc mice were approximately $34 \%$ and $23 \%$ of Hpx levels in the plasma of untreated Townes-AA mice, respectively $(p<0.01)$.

As shown in Figure 4A, wt-Hpx gene transfer-treated NY1DD mice at $1 \mathrm{~h}$ had significantly less heme-induced microvascular stasis $(8.9 \pm 3.4 \%)$ than Luc- $(34.9 \pm 3.4 \%)$ or LRS- $(32.6 \pm 1.9 \%)$ treated mice, supporting a cytoprotective role for Hpx in SCD $(p<0.05)$. Similar responses (Figure $4 \mathrm{~B}$ ) were found in the 


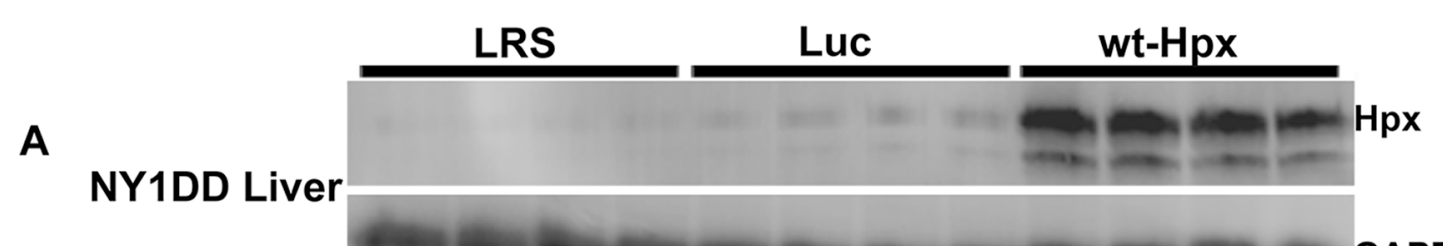

GAPDH

B
Townes-SS Liver

- - - - - - - - - - - - - -
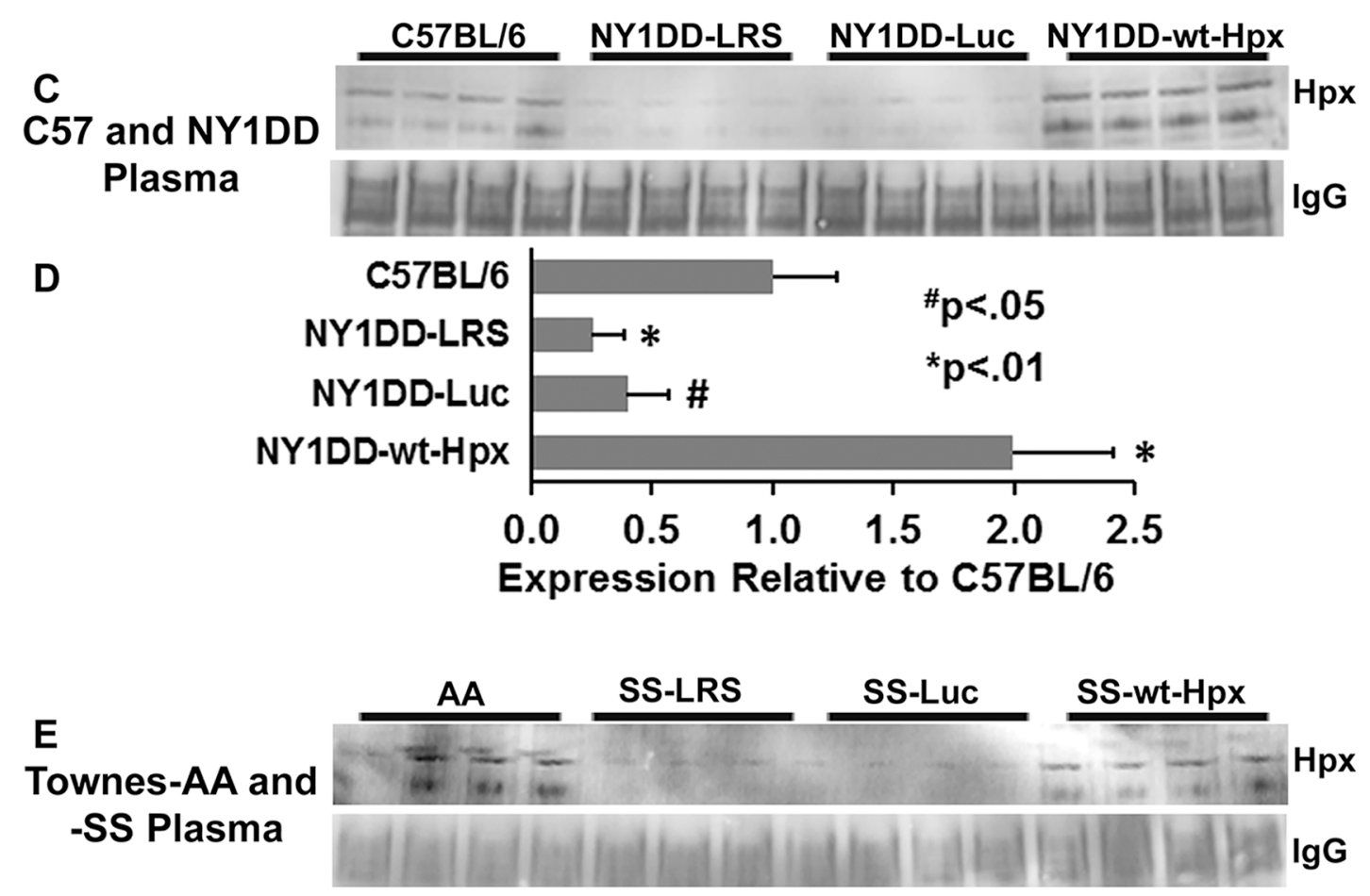

$\mathbf{F}$

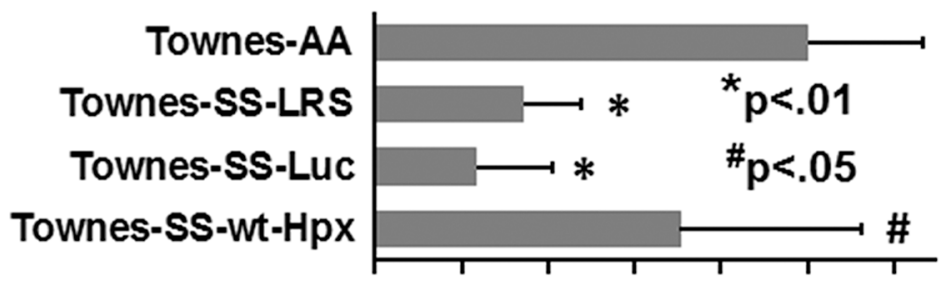

$\begin{array}{llllllll}0.0 & 0.2 & 0.4 & 0.6 & 0.8 & 1.0 & 1.2\end{array}$

Expression Relative to Townes-AA

Figure 3. Hemopexin gene therapy increases hemopexin expression in livers and plasma of sickle mice. NY1DD (A, C and D) and Townes-SS (B, E and F) mice were hydrodynamically infused with lactated Ringer's solution (LRS), Sleeping Beauty-100X transposase $(S B 100 X)+$ luciferase $(L U C)$, or SB100X + wt-Hpx $(n=4)$. Liver and plasma samples were collected 4 wks later after measurement of heme-induced stasis and run on western blots. Liver microsomes from NY1DD (A) and Townes-SS (B) mice were immunostained for hemopexin (Hpx) (68 kDa) and GAPDH (32 kDa). Plasma samples from treated NY1DD mice and untreated C57BL/6 control mice (C) and treated Townes-SS mice and untreated Townes-AA control mice (E) were immunostained for Hpx and lgG (155 kDa). Relative Hpx band intensities are presented in (D) and (F). In (D), \#p $<0.05$ versus C57BL/6 and ${ }^{*} p<0.01$ versus C57BL/6. In (F), ${ }^{*} p<0.05$ Townes-SS-wt-Hpx versus Townes-SS-LRS or Townes-SS-Luc and ${ }^{*} p<0.01$ Townes-SS-LRS or Townes-SS-Luc versus Townes-AA. 


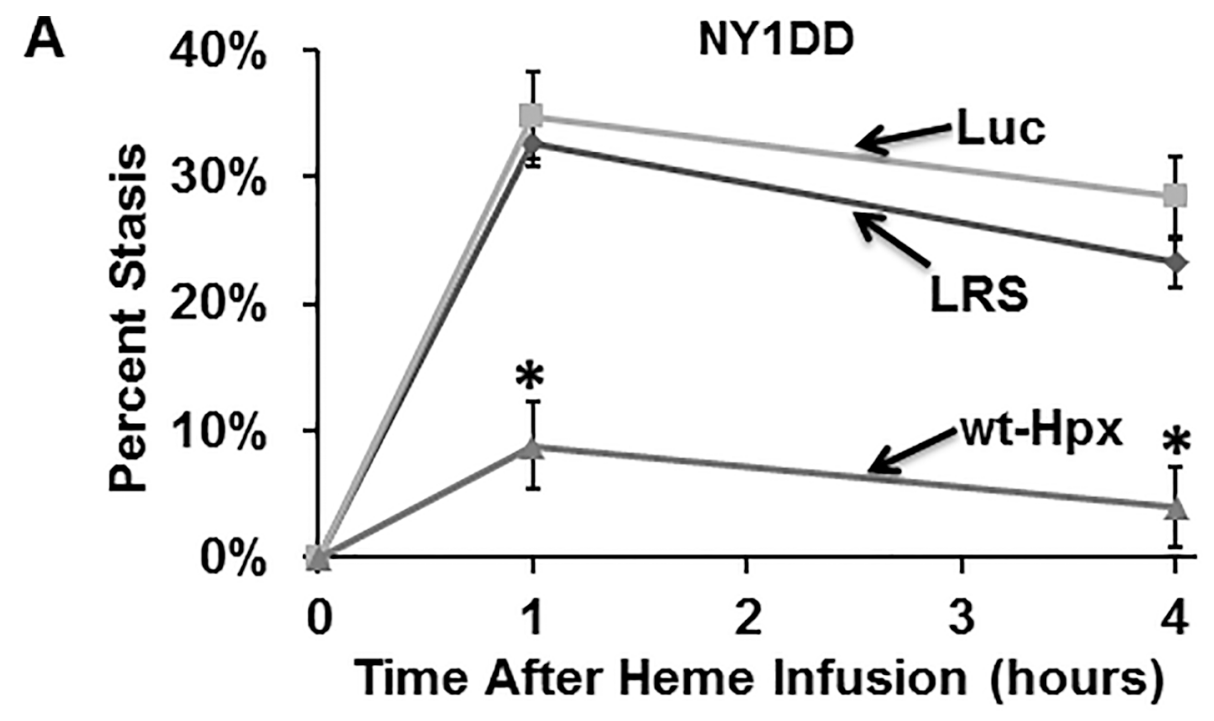

B

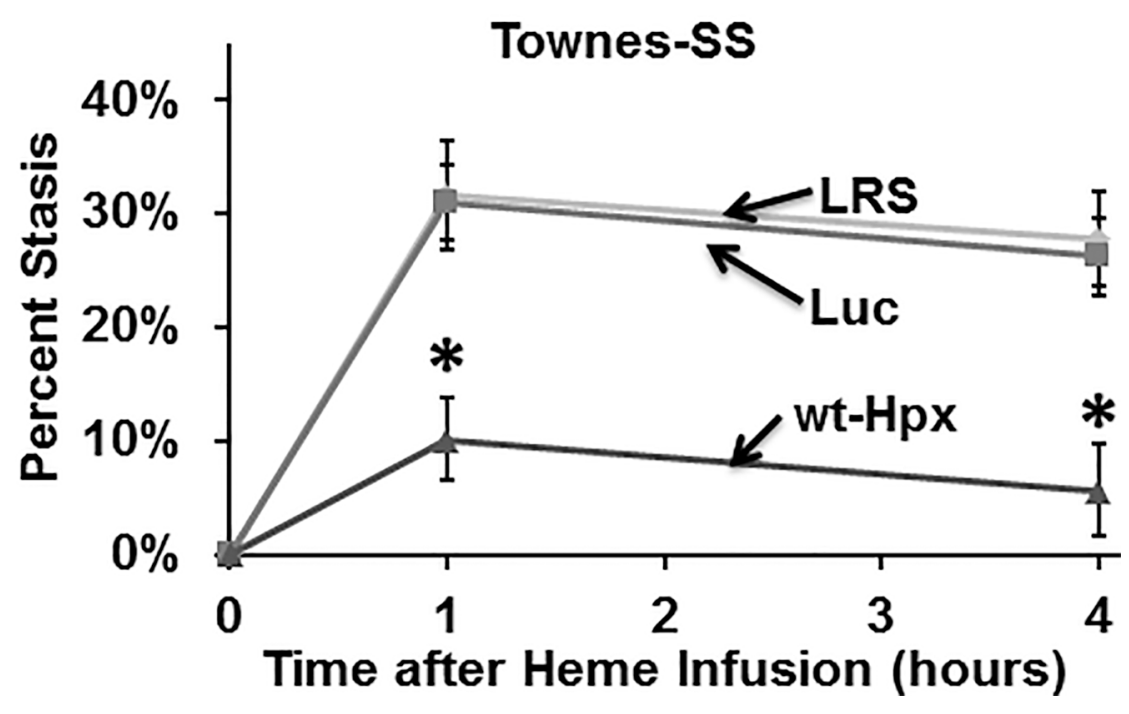

Figure 4. Hemopexin gene therapy inhibits heme-induced microvascular stasis in sickle mice. NYIDD (A) and Townes-SS (B) mice were hydrodynamically infused with lactated Ringer's solution (LRS), SB100X + LuC, or SB100X + wt-Hpx (NY1DD $(n=4)$ and Townes-SS: LRS and wt-Hpx $(n=3)$ and Luc $(n=2))$. DSFCs were implanted 4 wks later and microvascular stasis was measured at $1 \mathrm{~h}$ and $4 \mathrm{~h}$ after infusion of heme $(3.2 \mu \mathrm{mols} / \mathrm{kg})$. Percentage of stasis (mean $\pm \mathrm{SD}$ ) was calculated at each time point. ${ }^{*} P<0.05$ for wt-Hpx compared with LRS.

more severe hemolytic Townes-SS SCD mouse model, where wt-Hpx gene transfer similarly afforded protection.

To investigate the mechanism of wt-Hpx cytoprotective effects, we assessed the effects of Hpx gene transfer in the livers of NY1DD mice. Four weeks after wt-Hpx gene transfer, livers from
NY1DD mice had increased nuclear Nrf2 (Figure 5A), Hpx receptor (CD91/ LRP1, Figure 5B) and heme oxygenase-1 (HO-1, Figure 5C) relative to a GAPDH loading control (Figure 5D). These data are consistent with heme/Hpx uptake in the liver and activation of signaling to induce nuclear Nrf2 activation and CD91/
LRP1 and HO-1 synthesis. Wt-Hpx induces an antiinflammatory response, as evidenced by a decrease in NF- $\kappa \mathrm{B}$ activation in NY1DD liver nuclear extracts (Supplemental Figure 2), as assessed by decreased NF- $\kappa$ B phospho-p65 in wt-Hpx-treated animals relative to Luc- or LRS-infused sickle mice.

To test the role of heme and CD91/ LRP1 binding for protection by Hpx, we prepared a C-terminal Flag-tagged wild-type rat Hpx (wt-Hpx-c-Flag) and two missense (ms) rat Hpx constructs. In one ms-Hpx construct ( $\mathrm{ms}-\mathrm{Hpx}_{\mathrm{HM}^{-\mathrm{c}}}{ }^{-}$ Flag), we used site-directed mutagenesis to change three histidine residues to alanines (H149A, H325A, H291A). These residues are believed to be involved in heme-binding (53). In the second ms-Hpx construct ( $\mathrm{ms}-\mathrm{Hpx}_{\mathrm{RM}}$-Flag), two amino acids at the putative Hpxto-CD91/LRP1 receptor-binding site (R150A and E152A) were mutated to alanines (44). We expressed these proteins in $\mathrm{CHO}$ cells and purified them from the media by affinity chromatography using an anti-Flag affinity column (Supplemental Figure 3).

Next, we tested the translated wt- and ms-Hpx constructs for their heme-binding capability. Heme (iron-protoporphyrin IX) bound to Hpx has a peak in absorbance at $414 \mathrm{~nm}$ (49). As seen in Figure 6A, shifts of UV-Vis spectrophotometric scans indicates that wt-Hpx-c-Flag binds heme similar to commercial rat Hpx purified from blood. However, the

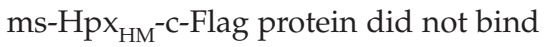

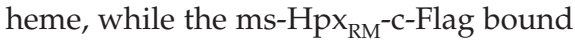
heme normally (Figure 6B).

To demonstrate the binding of heme/ Hpx to CD91/LRP1 on hepatocytes, HepG2 human hepatocytes were cultured, and binding of wt-Hpx-c-Flag, $\mathrm{Hpx}_{\mathrm{HM}^{-}}{ }^{\mathrm{C}-\text { Flag }}$ and $\mathrm{ms}-\mathrm{Hpx}_{\mathrm{RM}^{-}}{ }^{\mathrm{C}}-\mathrm{Flag}$, with and without bound heme, was assessed using Cy3/red fluorescent labeled antibodies to Flag and FITC/green fluorescent labeled antibodies to CD91/ LRP1. All the hepatocyte cells expressed CD91/LRP1 on the cell surface regardless of the incubation conditions (Figure 6C). In the absence of heme, no Hpx-flag 


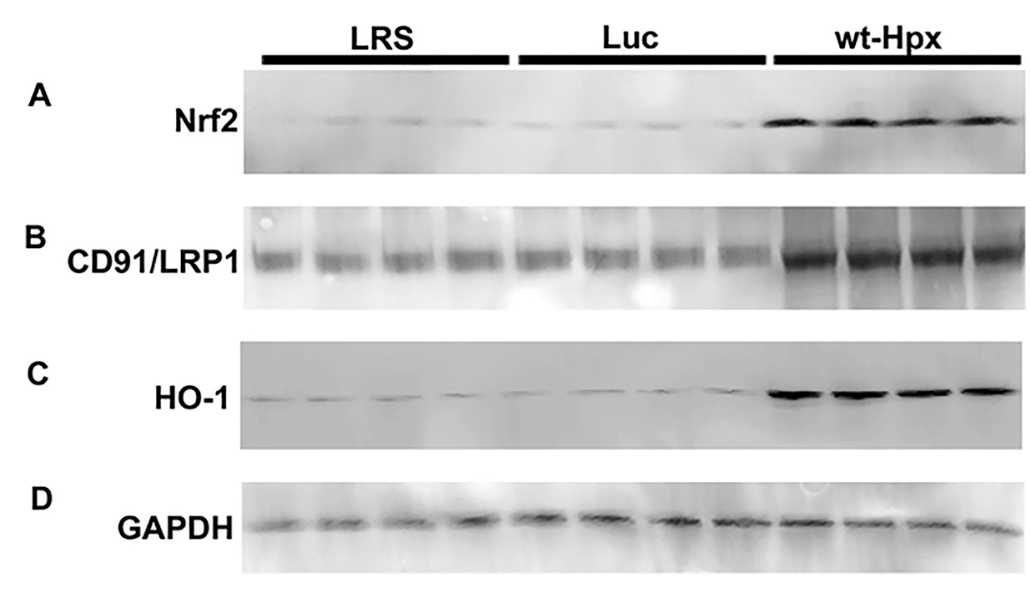

Figure 5. Hemopexin gene therapy increases Nrf2, LRP1/CD91 and heme oxygenase-1 (HO-1) expression in the livers of NY1DD sickle mice. NY1DD mice were hydrodynamically infused with lactated Ringer's solution (LRS), SB100X + Luc or SB100X + wt-Hpx $(n=4)$. Livers were harvested 4 wks later after measurement of heme-induced stasis and used for western blots. (A) Liver nuclear extracts were immunostained for (A) Nrf2 (MW 98 kDa), and liver microsomes were immunostained for (B) the hemopexin receptor (CD91/LRP1, $91 \mathrm{kDa}$ ), (C) HO-1 (32 kDa) and (D) a GAPDH (32 kDa) loading control. binding to cells was detected with any of the recombinant Hpx-flag proteins (top panels). However, in the presence of heme, wt-Hpx-flag bound to HepG2 cells (middle panel, second from left) and appeared to be colocalized (orange) with CD91/LRP1. However, the ms- $\mathrm{Hpx}_{\mathrm{HM}^{-}}$ Flag that does not bind heme and ms$\mathrm{Hpx}_{\mathrm{RM}}$-Flag that does not bind CD91/LRP1 showed no binding to HepG2 cells in the presence of heme (middle panels, third and fourth from left). The binding of wtHpx-Flag to HepG2 cells seems specific for wt-Hpx, since a 20-fold excess of purified human plasma Hpx inhibited binding of the wt-Hpx in the presence of heme (bottom panel, second from left).

To determine whether heme binding or receptor binding is critical for protection against heme-induced microvascular stasis, we hydrodynamically infused

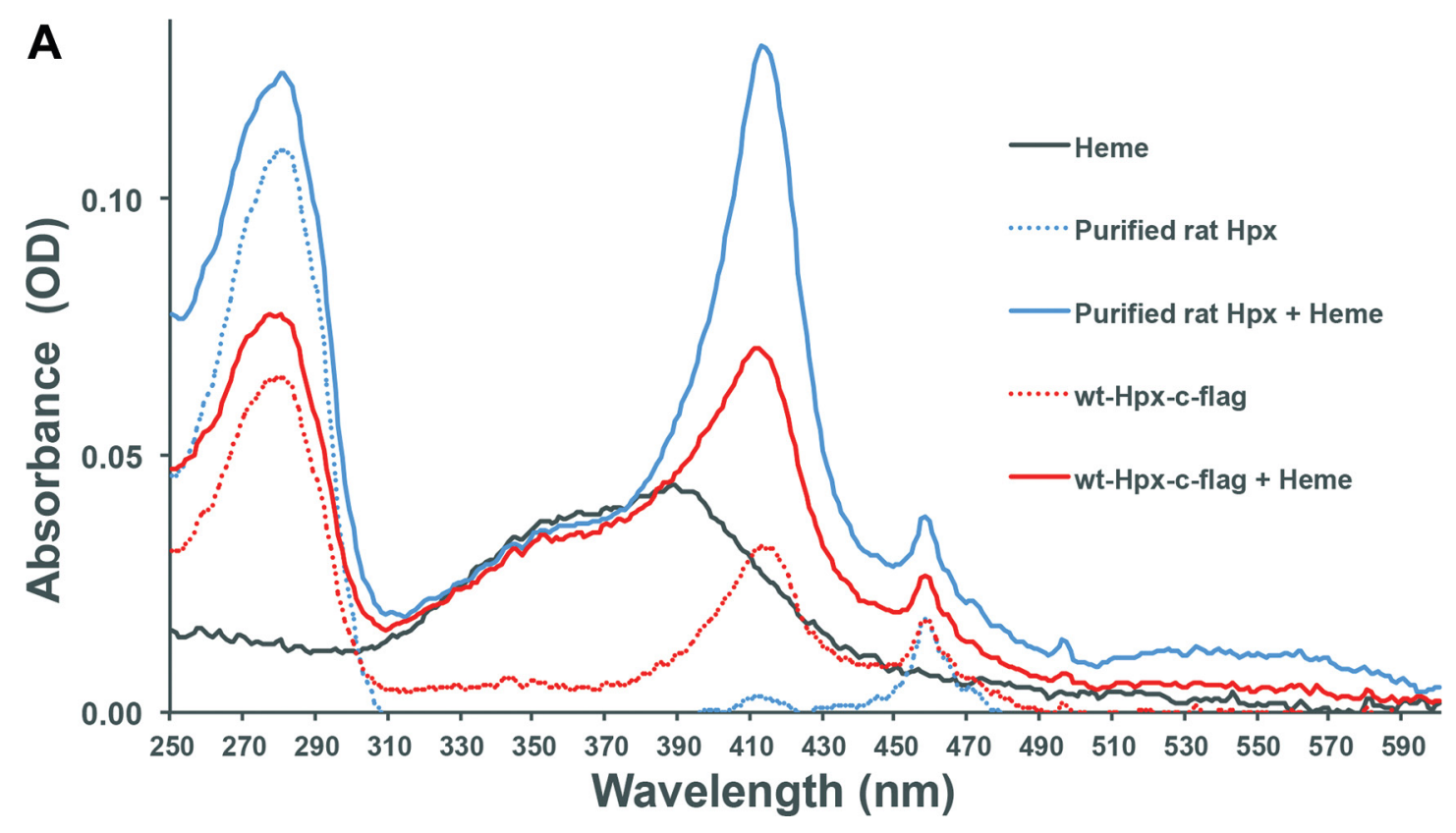

Figure 6. Characterization of heme- and receptor-binding by recombinant flagged wt-Hpx, ms-Hpx $\mathrm{HM}_{\mathrm{H}}$ and ms-Hpx $\mathrm{RM}_{\mathrm{m}}$. Wt-Hpx-C-Flag, $\mathrm{ms}^{-} \mathrm{Hpx}_{\mathrm{HM}}-\mathrm{C}-\mathrm{Flag}$ and $\mathrm{ms}-\mathrm{Hpx}_{\mathrm{RM}}-\mathrm{C}$-Flag plasmids were expressed in Chinese hamster ovary $(\mathrm{CHO})$ cells and the recombinant Hpx proteins were purified from the $\mathrm{CHO}$ serum-free media $4 \mathrm{~d}$ after transfection by anti-flag affinity chromatography, as described in Materials and Methods. ( $A$ and $B$ ) Heme-binding of recombinant and purified rat Hpx was assessed by UV/Vis absorption spectrometry (250-600 nm). Heme bound to

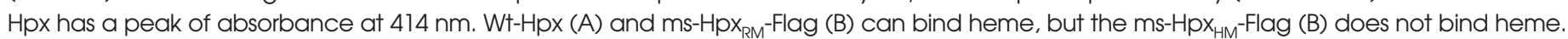
(C) Binding of the recombinant flag Hpx proteins ( $1 \mu \mathrm{M})$ to HepG2 cells was assessed by immunofluorescence using and anti-flag lgG (Cy3/ red) in the presence and absence of heme $(1 \mu \mathrm{M})$. A 20-fold excess of purified human Hpx $(20 \mu \mathrm{M})+\mathrm{wt}-\mathrm{Hpx}$-Flag $(1 \mu \mathrm{M})+$ heme $(1 \mu \mathrm{M})$ was used to assess the specificity of binding (C, bottom panels). To determine co-localization of wt-Hpx + heme with CD91/LRP1, HepG2 cells were double immunostained for flag (Cy3/red) and CD91/LRP1 (FITC/green). White bar of scale equals $20 \mu \mathrm{M}$. 


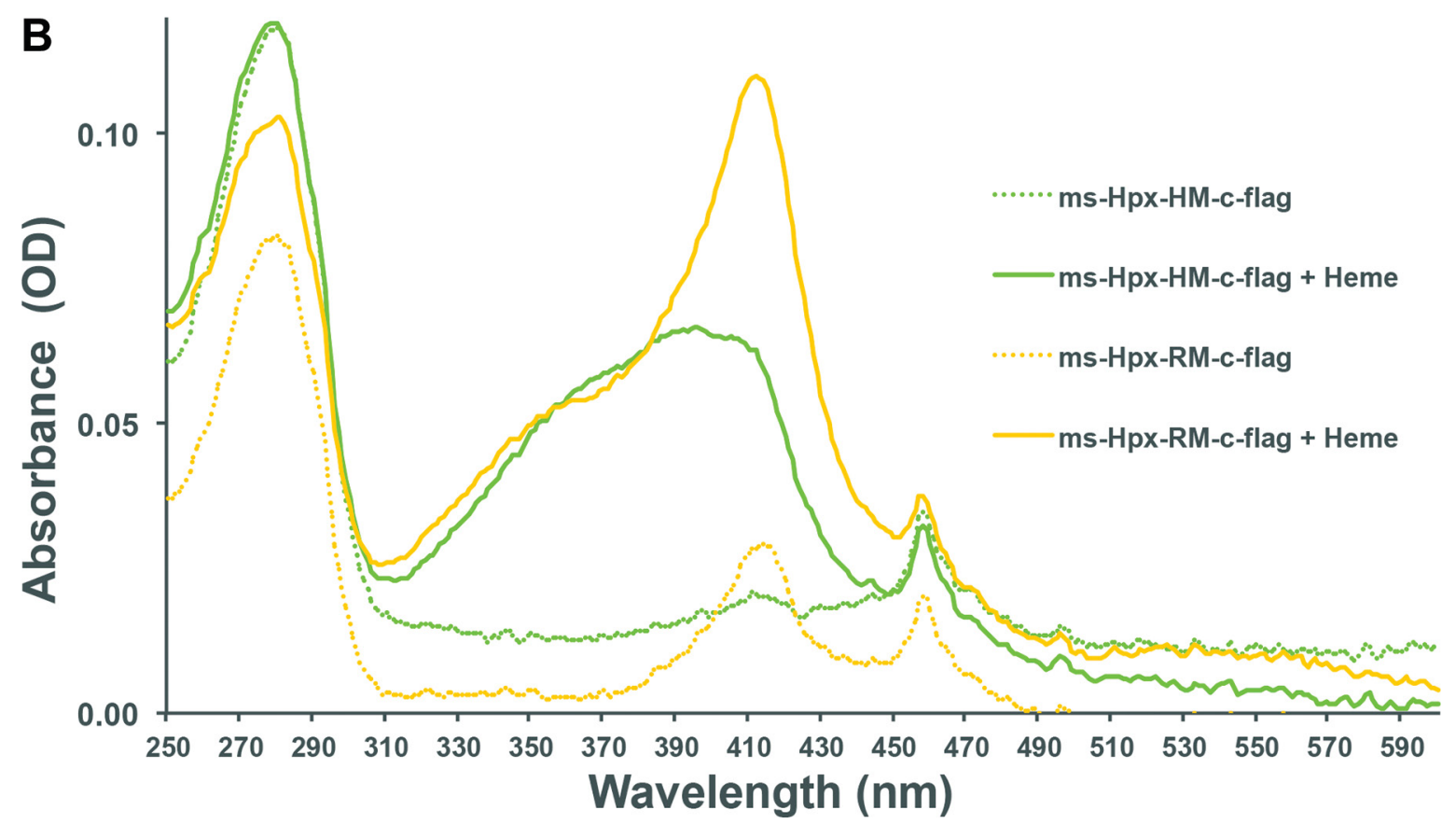

C
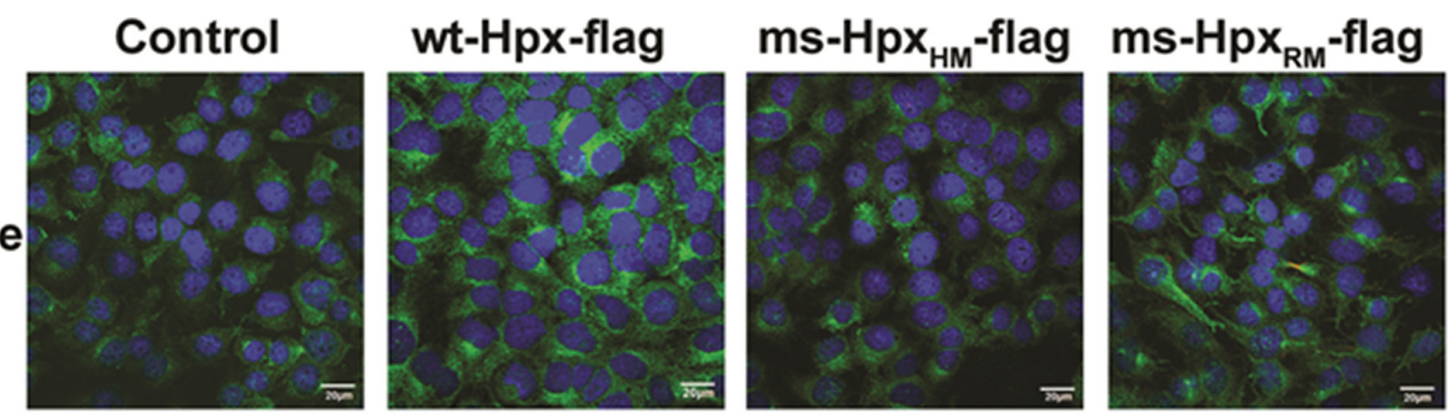

(-) Heme
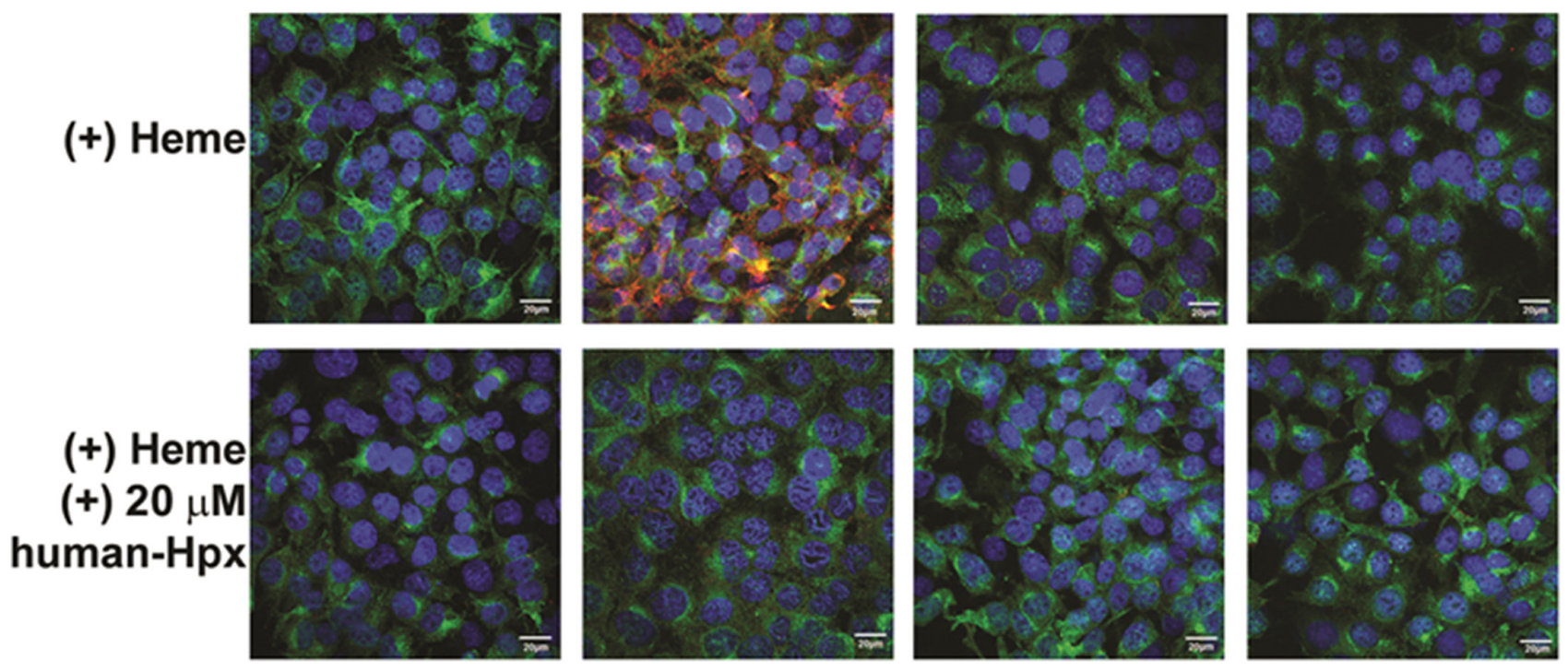

Figure 6. Continued. 
SB100X plus wt-Hpx, ms-Hpx $\mathrm{HM}_{\mathrm{HM}}$ or ms-Hpx $x_{\text {RM }}$ plasmids without Flag tags into NY1DD mice. After 4 wks, rat Hpx mRNA was assessed in the liver, heme levels were measured in plasma and heme-induced stasis was assessed with DSFCs. Rat Hpx mRNA was increased similarly in the livers of mice treated with wt-Hpx, ms-Hpx $\mathrm{HM}_{\mathrm{HM}}$ and $\mathrm{ms}-\mathrm{Hpx}_{\mathrm{RM}}$ compared with mice infused with LRS or Luc (Supplemental Figure 4).

Surprisingly, there were no significant differences in plasma heme or $\mathrm{Hb}$ levels between mice infused with LRS, Luc, wt-Hpx, ms-Hpx ${ }_{\mathrm{HM}}$ or $\mathrm{ms}-\mathrm{Hpx}_{\mathrm{RM}}$ (Supplemental Figures 5A and B). However, there was a trend toward lower plasma heme in mice overexpressing wt-Hpx and ms-Hpx $x_{R M}$ and higher plasma heme in the $\mathrm{ms}^{-H p x_{\mathrm{HM}}}$ sickle mice. Plasma total heme and $\mathrm{Hb}$ heme levels were measured $4 \mathrm{~h}$ after infusion of hemin to measure stasis. Plasma samples were collected from NY1DD gene therapy mice after stasis measurement and $\sim 4 \mathrm{~h}$ after infusion of hemin. Plasma heme levels were unaffected by the hemin challenge used to induce stasis, as similar plasma heme and $\mathrm{Hb}$ levels were seen in NY1DD gene therapy mice without DSFCs and not challenged with hemin (data not shown).

When stasis was measured in NY1DD mice (Figure 7A), neither $\mathrm{ms}^{-\mathrm{Hpx}_{\mathrm{HM}}}$ $(28.8 \pm 6.6 \%)$ nor $\mathrm{ms}^{-\mathrm{Hpx}_{\mathrm{RM}}}(24.1 \pm 3.6 \%)$ protected against heme-induced stasis compared with mice expressing wt-Hpx $(8.9 \pm 3.4 \%, p<0.05)$. Thus, both heme binding to Hpx and clearance of Hpx/ heme via CD91/LRP1 are essential for protection from heme-mediated stasis.

Relative HO-1 protein expression in NY1DD livers was markedly higher in mice overexpressing wt-Hpx compared with mice overexpressing $\mathrm{ms}^{-} \mathrm{Hpx}_{\mathrm{HM}}$ or $\mathrm{ms}^{-\mathrm{Hpx}_{\mathrm{RM}}}$ (Figure 7B). Similarly HO-1 activity in livers was significantly increased in mice overexpressing wt-Hpx $(p<0.05)$, while HO-1 activity in the livers of sickle mice overexpressing $\mathrm{ms}^{-} \mathrm{Hpx}_{\mathrm{HM}}$ or $\mathrm{ms}$ $\mathrm{Hpx}_{\mathrm{RM}}$ was similar to that of mice treated with LRS or Luc (Figure 7C).

To see if HO-1 is important to Hpxmediated protection, we treated NY1DD
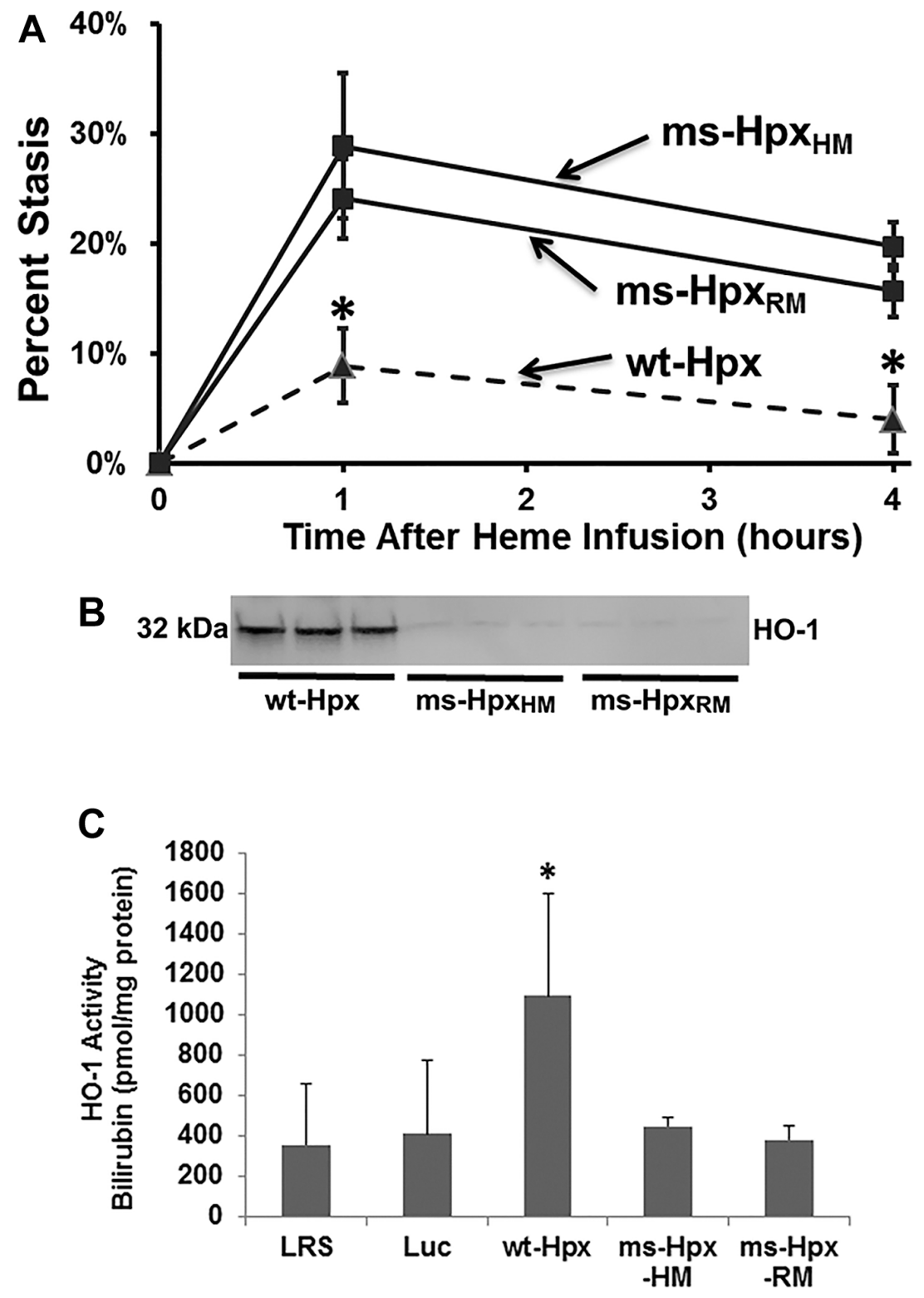

Figure 7. Wt-Hpx but not $\mathrm{ms}^{-H p x_{H M}}$ or $\mathrm{ms}^{-H p x_{R M}}$ decreased heme-induced stasis and increased $\mathrm{HO}-1$, and was not protective when $\mathrm{HO}-1$ was blocked by SnPP. (A) NY1DD mice were hydrodynamically infused with $S B 100 X+$ wt-Hpx $(n=4), S B 100 X+m_{s}-H_{p x}(n=3)$ or $S B 100 X+\operatorname{ms}^{-H p x_{R M}}(n=4)$ plasmids. DSFCs were implanted 4 wks later and microvascular stasis was measured at $1 \mathrm{~h}$ and $4 \mathrm{~h}$ after infusion of heme $(3.2 \mu \mathrm{mols} / \mathrm{kg})$. Percentage of stasis (mean $\pm \mathrm{SD}$ ) was calculated at each time point. ${ }^{*} p<0.05$ for wt-Hpx compared

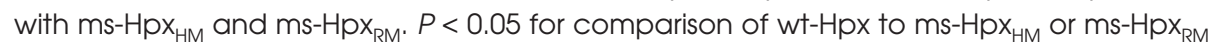
(B) Liver microsomes were immunostained for $\mathrm{HO}-1$ (32 kDa). (C) $\mathrm{HO}$ activity was measured in liver microsomes 4 wks after NYIDD mice were hydrodynamically infused with

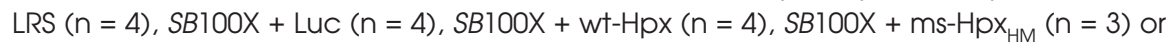
$S B 100 X+m_{s}-H_{p x}(n=4) . P<0.05$ for comparison of wt-Hpx to LRS, Luc, ms-Hpx $\mathrm{HM}_{\mathrm{RM}}$ or ms$\mathrm{HPx}_{\mathrm{RM}}$ (D) Treatment of NYIDD sickle mice overexpressing wt-Hpx with the HO inhibitor tin protoporphyrin (SnPP, $40 \mu \mathrm{mols} / \mathrm{kg} \times 3 \mathrm{~d}$, intraperitoneally) reversed the protection afforded by wt-Hpx. ${ }^{*} P<0.05$ for comparison of wt-Hpx to wt-Hpx + SnPP. The wt-Hpx data (dashed line) in A and D were taken from Figure 4A.

Continued on the next page 


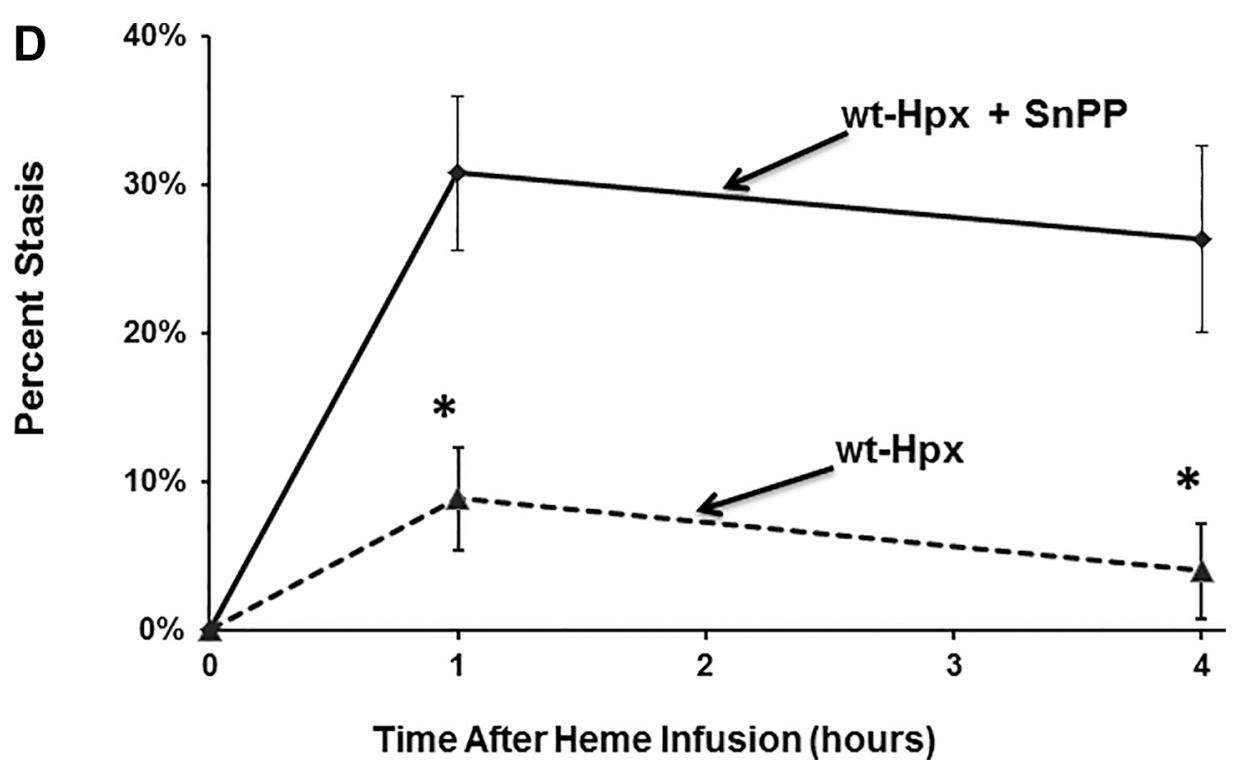

Figure 7. Continued.

sickle mice overexpressing wt-Hpx with the HO-1 inhibitor SnPP (Figure 7D). This treatment reversed the protection (stasis $=30.8 \pm 5.2 \%$ ) afforded by wt-Hpx $1 \mathrm{~h}$ post-heme infusion to levels similar to those of control mice treated with LRS, suggesting that delivery of heme to the liver via CD91/LRP1 and signaling of Nrf2 for HO-1 activity induction $(54,55)$ are essential to the protection afforded by Hpx in SCD.

\section{DISCUSSION}

We have shown that murine sickle mice, like patients with SCD, have decreased levels of plasma Hpx. This depletion of Hpx, due to ongoing hemolysis in SCD, imparts a vulnerability to heme-mediated toxicity. $\mathrm{Hpx}^{-/-}$mice transplanted with NY1DD BM had significantly more microvascular stasis in response to heme challenge than $\mathrm{Hpx}^{+/+}$mice transplanted with NY1DD BM. Gene transfer using SB100X + wtHpx bolstered defenses of both NY1DD and Townes-SS mice against heme-mediated vasoocclusion. Increasing hepatic Hpx production in SCD mice via gene transfer increased plasma Hpx levels and induced hepatic Nrf2,
CD91/LRP1 and HO-1 expression, and decreased NF- $\kappa \mathrm{B}$ activation.

$\mathrm{HO}-1$, ferritin heavy chain, haptoglobin, hemopexin and multiple other antioxidant genes have been previously identified as Nrf2-responsive in studies comparing gene expression in wild-type and Nrf2 null mice with and without Nrf2 agonists (56-61). The protection against vasoocclusion afforded by Hpx gene therapy appeared to be dependent on HO-1 activity, as SnPP, a potent inhibitor of HO-1 activity, reversed the antivasoocclusive properties of $\mathrm{Hpx}$ gene therapy. However, SnPP has many nonspecific effects, and it is possible that other cytoprotective antioxidant genes activated by Nrf2 could play a role in the antiinflammatory and antivasoocclusive effects induced by Hpx. Additional studies in Nrf2- and HO-1-deficient sickle mice are needed to confirm these observations.

HO-1 induction in response to hemopexin/heme is mediated primarily by Nrf2 activation $(23,54)$. To our knowledge, increased CD91/LRP1 expression in response to Nrf2 activation has not been previously reported. We have identified three putative Nrf2 antioxidant response elements (AREs) located $-45 \mathrm{k}$ to $-10 \mathrm{k}$ upstream from the transcription start site of the human LRP1/CD91 gene (data not shown). In addition, there are many transcription factor binding sites in the CD91/LRP1 promoter area (Genecard), including 2 STAT1 sites and 2 MYC sites; both STAT1 and MYC have AREs and can be upregulated by Nrf2 (56). Therefore, CD91/LRP1 expression might be regulated by Nrf2 directly or indirectly.

CD91/LRP1 is expressed on hepatoctyes; other cell types, including macrophages, neurons and syncytiotrophoblasts, also express CD91/LRP1 (62), yet the majority of Hpx-heme clearance occurs in the liver (31). It is possible this is a bulk effect due to the sheer number of CD91/LRP1 receptors in the liver. The roles of other CD91/LRP1 expressing cell types and the possible contribution of alternative receptors in Hpx-heme clearance remain to be studied. We demonstrated that both heme binding to Hpx and clearance of Hpx/heme via CD91/ LRP1 are essential for induction of $\mathrm{HO}-1$ and protection from heme-mediated stasis (Figures 6 and 7).

Somewhat surprisingly, plasma heme levels measured $4 \mathrm{~h}$ after hemin challenge to induce stasis were not altered by Hpx gene transfer (Supplemental Figure 5) or by the hemin challenge (data not shown). The rationale for using $3.2 \mu$ moles $/ \mathrm{kg}$ hemin to induce stasis was that it translated to an initial heme concentration in blood of $\sim 50 \mu \mathrm{M}$. A small sample of SCD patients were reported to have plasma heme levels up to $30.6 \mu \mathrm{g} / \mathrm{mL}$, which is equivalent to $\sim 50 \mu \mathrm{M}$ (27). At our infused dose of hemin, plasma heme levels were completely normalized within $4 \mathrm{~h}$, likely due to the rapid turnover of plasma heme in SCD. Plasma heme levels reflect only a snapshot in time and do not reflect the rapid throughput of heme from the sickle RBC to the tissues, which occurs continuously in SCD. Our data do not reveal the production and clearance rates of plasma heme or hemopexin. One possible explanation for unchanged plasma 
heme levels despite increased liver and plasma hemopexin levels is that the net input (hemolysis) and output (clearance) rates of plasma heme were unchanged in sickle mice receiving wt-Hpx gene therapy. The increased levels of plasma hemopexin may provide a sink or vehicle to deliver plasma heme safely to the liver for degradation by HO-1 without activating inflammatory responses in the vessel wall $(2,31,32,63)$ and without necessarily increasing the plasma heme clearance rate. In contrast, when plasma levels of hemopexin are depleted, heme is more oxidatively reactive and able to promote proinflammatory responses in endothelium and in monocyte/macrophages via TLR4 signaling $(2,9,10)$. Thus, the plasma heme that was circulating in wt-Hpx-treated sickle mice may have been diverted away from vessel walls and rendered less reactive, but without a faster clearance rate from plasma.

Inflammation and vasoocclusion were inhibited, likely due to delivery of heme to the liver by $\mathrm{Hpx} /$ heme binding to CD91/LRP1. Overexpression of recombinant Hpx that was deficient in heme binding or CD91/LRP1 binding did not protect against heme-induced stasis. We conclude that in addition to redirecting heme from activating the vasculature via TLR4 and oxidative stress, the ability of Hpx to deliver heme to the liver for induction of HO-1 is important for protection against vasoocclusion.

Nearly 50 years ago, Ursula Muller-Eberhard measured Hpx and haptoglobin levels in various hemolytic states, showing that SCD patients had the lowest levels of both proteins (27). Invariably, Hpx levels were lowest when heme concentrations were highest. The implications of these findings suggested that Hpx may be a marker for hemolysis, but no suggestion was made regarding its role in the pathophysiology of SCD.

As the structure and function of $\mathrm{Hpx}$ was made known, the clear role in heme clearance during intravascular hemolysis was determined. Hpx has an extraordinary affinity for heme $\left(\mathrm{K}_{\mathrm{d}} \sim 10^{-13} \mathrm{M}\right)$, while albumin, which has a $60-$ to 70 -fold higher concentration in plasma, can readily give up heme to $\mathrm{Hpx}$ (52). We and others have shown that in sickle mice with decreased Hpx, albumin is not sufficient to prevent heme toxicity $(2,10,31,32)$. Safe clearance of heme from plasma rapidly occurs (within minutes) by receptor-mediated endocytosis principally in the liver, in part via CD91/ LRP1 $(24,37)$. In the absence of Hpx, heme can dissociate from RBC-derived microparticles or albumin and bind to cells or lipoproteins. This heme can be toxic, as we have previously shown, augmenting oxidative damage to the vasculature $(7,64,65)$, but can be blocked by Hpx. Fortunately, adaptation to chronic heme exposure of the vasculature occurs due to induction of HO-1 and heavy chain ferritin, which are cytoprotective (22,65-68). The consequence of heme/ Hpx binding to CD91/LRP1 is activation of Nrf2 and the subsequent activation of the antioxidant response elements inducing $\mathrm{HO}-1$ and other cytoprotectants including ferritin $(23,54,69-74)$. We have previously shown in murine sickle mice that overexpression of HO-1 either by gene transfer or pharmacologically has remarkable antiinflammatory, cytoprotective and antivasoocclusive actions.

The present studies similarly support a protective role for Hpx delivering heme to the liver and inducing HO-1. Exogenous supplementation of Hpx can prevent heme-induced endothelial toxicity and improve cardiovascular function in mice. Vinchi et al. showed that $\mathrm{Hpx}^{-/-}$ mice had more reactive oxygen species and vascular activation $(31,32)$. Intraperitoneal administration of exogenous Hpx twice per week to sickle and thalassemic mice decreased markers of oxidation and endothelial activation (31). Furthermore, blood pressure decreased and cardiac function improved in the Hpx-treated mice. Recently, Vinchi et al. also showed that exogenous Hpx attenuated the activation of sickle mouse macrophages (30).

Ghosh et al. showed that hemin infusion into sickle mice causes pulmonary injury similar to the acute chest syndrome seen in SCD patients (10). Inhibition of
TLR4 with TAK-242 or binding heme with Hpx ameliorated this toxicity. This suggests that activation of TLR4 by hemin promotes the vascular injury, but Hpx could prevent this response. Bozza et al. showed that heme can activate a macrophage inflammasome response via TLR4 unique from lipopolysaccharide $(9,75)$. We showed that heme activates endothelial TLR4 signaling and TAK-242 or exogenous Hpx prevents heme-induced microvascular stasis (2). Our studies also showed that hemoglobin-induced stasis in sickle mice could be blunted by Hpx and that heme dissociates from hemoglobin to interact with TLR4 and promote P-selectin and von Willebrand factor expression on endothelium. Free methemoglobin, which can be increased in the oxidative milieu of SCD, readily gives up heme (1-3). Camus et al. showed that SCD patients have increased red cell microparticles with increased methemoglobin and heme that can activate endothelial cells, which can be prevented by addition of Hpx, suggesting heme availability in the microparticle (4). Even without exogenous hemin infusion, Townes-SS mice spontaneously develop microvascular stasis, which can be blocked by Hpx supplementation (2).

The advantage of gene transfer compared with supplementation with exogenous hemopexin is that with gene transfer, the Hpx is being continually produced by the liver, whereas with exogenous hemopexin supplementation, the hemopexin must be infused at regular intervals. Current studies are under way in Townes-SS mice to determine the optimal dosing schedule for exogenous hemopexin supplementation.

In the present studies, plasma $\mathrm{Hpx}$ increased upon treatment with wt-Hpx gene transfer. The protection afforded by Hpx was dependent on heme binding to Hpx, and the heme/Hpx complex binding to CD91/LRP1 as gene transfer with $\mathrm{ms}^{-} \mathrm{Hpx}_{\mathrm{HM}}$ or $\mathrm{ms}-\mathrm{Hpx}_{\mathrm{RM}}$ proteins did not afford protection. The above studies of exogenous Hpx supplementation suggest that Hpx prevented interaction with TLR4 or other membrane molecules on endothelial and inflammatory cells to modulate 
inflammation and vasoocclusion. Yet these present studies do not show a decrease in plasma heme levels, but did show protection against subsequent heme infusion in sickle mice. Possibly the massive load of free hemoglobin from daily hemolysis in the sickle mice could overwhelm the increase in plasma Hpx induced by gene transfer or the plasma heme measured in Hpx overexpressing mice included heme bound to Hpx. We have seen protection against hemoglobin or hypoxia/reoxygenation-induced vasoocclusion in sickle mice when HO-1 is induced pharmacologically or with gene transfer. Induction of the Nrf2 axis, with its antioxidant target genes like HO-1, is critical to cytoprotection in SCD. We recently reported that activation of Nrf2 with dimethyl fumarate provides induction of antiinflammatory responses and robust protection in sickle mice against heme-induced injury (76). A recent study amplified the importance of $\mathrm{Nrf} 2$ in SCD showing that ablation of KEAP-1, a negative regulator of $\mathrm{Nrf2}$, reduces inflammation in sickle mice (77).

\section{CONCLUSION}

We postulate that gene transfer of Hpx improves delivery of heme derived from hemolysis in sickle mice to liver CD91/LRP1, activating Nrf2 and cytoprotective responses. $\mathrm{Ms}-\mathrm{Hpx}_{\mathrm{HM}}$ and ms-Hpx ${ }_{\mathrm{RM}}$, which did not bind heme or CD91/LRP1, did not induce HO-1 in the liver. The reversal of protection by SnPP, which blocks HO-1 activity, supports this concept.

We speculate that Hpx supplementation may be beneficial in SCD patients in preventing or treating hemolytic crises or the acute chest syndrome. Other hemoglobin-binding proteins are also likely to be beneficial, such as haptoglobin $(26,36,78,79)$. Perhaps a combination of plasma Hpx and haptoglobin infusions would be particularly effective.

\section{ACKNOWLEDGEMENTS}

We would like to thank Dr Robert Hebbel for constructive criticism.

\section{DISCLOSURE}

The authors of this paper, Drs. Vercellotti and Belcher, have received research funding from CSL Behring. The research was supported by National Heart, Lung, and Blood Institute grant R01 2R01HL114567-04.

\section{REFERENCES}

1. Bunn HF, Jandl JH. (1968) Exchange of heme among hemoglobins and between hemoglobin and albumin. J. Biol. Chem. 243:465-75.

2. Belcher JD, et al. (2014) Heme triggers TLR4 signaling leading to endothelial cell activation and vaso-occlusion in murine sickle cell disease. Blood. 123:377-90.

3. Umbreit J. (2007) Methemoglobin-it's not just blue: a concise review. Am. J. Hematol. 82:134-44.

4. Camus SM, et al. (2015) Circulating cell membrane microparticles transfer heme to endothelial cells and trigger vasoocclusions in sickle cell disease. Blood. 125:3805-14.

5. Wagener FA, Abraham NG, van Kooyk Y, de Witte T, Figdor CG. (2001) Heme-induced cell adhesion in the pathogenesis of sickle-cell disease and inflammation. Trends Pharmacol. Sci. 22:52-54

6. Yamauchi T, Lin Y, Sharp FR, Noble-Haeusslein LJ. (2004) Hemin induces heme oxygenase-1 in spinal cord vasculature and attenuates barrier disruption and neutrophil infiltration in the injured murine spinal cord. J. Neurotrauma. 21:1017-30

7. Balla G, Vercellotti GM, Muller-Eberhard U, Eaton J, Jacob HS. (1991) Exposure of endothelial cells to free heme potentiates damage mediated by granulocytes and toxic oxygen species. Lab. Invest. 64:648-55.

8. Jeney V, et al. (2002) Pro-oxidant and cytotoxic effects of circulating heme. Blood. 100:879-87.

9. Figueiredo RT, et al. (2007) Characterization of heme as activator of Toll-like receptor 4. J. Biol. Chem. 282:20221-29.

10. Ghosh S, et al. (2013) Extracellular hemin crisis triggers acute chest syndrome in sickle mice. J. Clin. Invest. 123:4809-20.

11. Kaul DK, Hebbel RP. (2000) Hypoxia/reoxygenation causes inflammatory response in transgenic sickle mice but not in normal mice. J. Clin. Invest. 106:411-20.

12. Kaul DK, et al. (2004) Anti-inflammatory therapy ameliorates leukocyte adhesion and microvascular flow abnormalities in transgenic sickle mice. Am. J. Physiol. Heart Circ. Physiol. 287: H293-301.

13. Kaul DK, et al. (2000) Monoclonal antibodies to alphaVbeta3 (7E3 and LM609) inhibit sickle red blood cell-endothelium interactions induced by platelet-activating factor. Blood. 95:368-74.

14. Frenette PS. (2004) Sickle cell vasoocclusion: heterotypic, multicellular aggregations driven by leukocyte adhesion. Microcirculation. 11:167-77.
15. Turhan A, Weiss LA, Mohandas N, Coller BS, Frenette PS. (2002) Primary role for adherent leukocytes in sickle cell vascular occlusion: a new paradigm. Proc. Natl. Acad. Sci. U.S.A. 99:3047-51.

16. Parise LV, Telen MJ. (2003) Erythrocyte adhesion in sickle cell disease. Curr. Hematol. Rep. 2:102-08.

17. Telen MJ. (2007) Role of adhesion molecules and vascular endothelium in the pathogenesis of sickle cell disease. Hematology Am. Soc. Hematol. Educ. Program. 84-90.

18. Berberat PO, et al. (2003) Heavy chain ferritin acts as an antiapoptotic gene that protects livers from ischemia reperfusion injury. FASEB J. 17:1724-26.

19. Otterbein LE, Soares MP, Yamashita K, Bach FH. (2003) Heme oxygenase-1: unleashing the protective properties of heme. Trends Immunol. 24:449-55.

20. Balla G, et al. (1992) Ferritin: a cytoprotective antioxidant stratagem of endothelium. J. Biol. Chem. 267:18148-53.

21. Belcher JD, et al. (2006) Heme oxygenase-1 is a modulator of inflammation and vaso-occlusion in transgenic sickle mice. J. Clin. Invest. 116:808-16.

22. Vercellotti GM, et al. (2014) H-ferritin ferroxidase induces cytoprotective pathways and inhibits microvascular stasis in transgenic sickle mice. Front. Pharmacol. 5:79.

23. Alam J, Smith A. (1989) Receptor-mediated transport of heme by hemopexin regulates gene expression in mammalian cells. J. Biol. Chem. 264:17637-40.

24. Smith A, Morgan WT. (1979) Haem transport to the liver by haemopexin. Receptor-mediated uptake with recycling of the protein. Biochem. J. 182:47-54.

25. Moestrup SK, Moller HJ. (2004) CD163: a regulated hemoglobin scavenger receptor with a role in the anti-inflammatory response. Ann. Med. 36:347-54.

26. Schaer DJ, Buehler PW, Alayash AI, Belcher JD, Vercellotti GM. (2013) Hemolysis and free hemoglobin revisited: exploring hemoglobin and hemin scavengers as a novel class of therapeutic proteins. Blood. 121:1276-84.

27. Muller-Eberhard U, Javid J, Liem HH, Hanstein A, Hanna M. (1968) Plasma concentrations of hemopexin, haptoglobin and heme in patients with various hemolytic diseases. Blood. 32:811-15.

28. Fagoonee S, et al. (2005) Plasma Protein Haptoglobin Modulates Renal Iron Loading. Am. J. Pathol. 166:973-83.

29. Li RC, et al. (2009) Heme-hemopexin complex attenuates neuronal cell death and stroke damage. J. Cereb. Blood Flow Metab. 29:953-64.

30. Vinchi F, et al. (2016) Hemopexin therapy reverts heme-induced proinflammatory phenotypic switching of macrophages in a mouse model of sickle cell disease. Blood. 127:473-86.

31. Vinchi F, et al. (2013) Hemopexin Therapy Improves Cardiovascular Function by Preventing Heme-Induced Endothelial Toxicity in Mouse Models of Hemolytic Diseases. Circulation. 127(12):1317-29. 
32. Vinchi F, Gastaldi S, Silengo L, Altruda F, Tolosano E. (2008) Hemopexin prevents endothelial damage and liver congestion in a mouse model of heme overload. Am. J. Pathol. 173:289-99.

33. Baek JH, et al. (2012) Hemoglobin-driven pathophysiology is an in vivo consequence of the red blood cell storage lesion that can be attenuated in guinea pigs by haptoglobin therapy. J. Clin. Invest. 122:1444-58.

34. Boretti FS, et al. (2009) Sequestration of extracellular hemoglobin within a haptoglobin complex decreases its hypertensive and oxidative effects in dogs and guinea pigs. J. Clin. Invest. 119:2271-80.

35. Tolosano E, et al. (1999) Defective recovery and severe renal damage after acute hemolysis in hemopexin-deficient mice. Blood. 94:3906-14.

36. Smith A, McCulloh RJ. (2015) Hemopexin and haptoglobin: allies against heme toxicity from hemoglobin not contenders. Front. Physiol. 6:187.

37. Hvidberg V, et al. (2005) Identification of the receptor scavenging hemopexin-heme complexes. Blood. 106:2572-79.

38. Fabry ME, Nagel RL, Pachnis A, Suzuka SM, Costantini F. (1992) High expression of human beta S- and alpha-globins in transgenic mice: hemoglobin composition and hematological consequences. Proc. Natl. Acad. Sci. U.S.A. 89:12150-54.

39. Wu LC, et al. (2006) Correction of sickle cell disease by homologous recombination in embryonic stem cells. Blood. 108:1183-88.

40. Belcher JD, Nath KA, Vercellotti GM. (2013) Vasculotoxic and pro-inflammatory effects of plasma heme: Cell signaling and cytoprotective responses. ISRN Oxid. Med. 2013: Article ID 831596.

41. Chen L, Zhang X, Chen-Roetling J, Regan RF. (2011) Increased striatal injury and behavioral deficits after intracerebral hemorrhage in hemopexin knockout mice. J. Neurosurg. 114:1159-67.

42. Wilber A, et al. (2006) RNA as a source of transposase for Sleeping Beauty-mediated gene insertion and expression in somatic cells and tissues. Mol. Ther. 13:625-30.

43. Xue X, et al. (2009) Stable gene transfer and expression in cord blood-derived CD34+ hematopoietic stem and progenitor cells by a hyperactive Sleeping Beauty transposon system. Blood. 114:1319-30.

44. Paoli M, et al. (1999) Crystal structure of hemopexin reveals a novel high-affinity heme site formed between two beta-propeller domains. Nat. Struct. Biol. 6:926-31.

45. Bell JB, et al. (2007) Preferential delivery of the Sleeping Beauty transposon system to livers of mice by hydrodynamic injection. Nat. Protoc. 2:3153-65.

46. Belcher JD, et al. (2010) Heme oxygenase-1 gene delivery by Sleeping Beauty inhibits vascular stasis in a murine model of sickle cell disease. J. Mol. Med. (Berl.) 88:665-75.
47. Longo PA, Kavran JM, Kim MS, Leahy DJ. (2014) Single cell cloning of a stable mammalian cell line. Methods Enzymol. 536:165-72.

48. Aydin H, Azimi FC, Cook JD, Lee JE. (2012) A convenient and general expression platform for the production of secreted proteins from human cells. JoVE.

49. Morgan WT, et al. (1988) Use of hemopexin domains and monoclonal antibodies to hemopexin to probe the molecular determinants of hemopexin-mediated heme transport. J. Biol. Chem. 263:8220-25.

50. Fairbanks VF, Ziesmer SC, O’Brien PC. (1992) Methods for measuring plasma hemoglobin in micromolar concentration compared. Clin. Chem. 38:132-40.

51. Kalambur VS, et al. (2004) Microvascular blood flow and stasis in transgenic sickle mice: utility of a dorsal skin fold chamber for intravital microscopy. Am. J. Hematol. 77:117-25.

52. Morgan WT, Liem HH, Sutor RP, MullerEberhard U. (1976) Transfer of heme from heme-albumin to hemopexin. Biochim. Biophys. Acta. 444:435-45.

53. Morgan WT, et al. (1993) Identification of the histidine residues of hemopexin that coordinate with heme-iron and of a receptor-binding region. J. Biol. Chem. 268:6256-62.

54. Alam J, et al. (1999) Nrf2, a Cap'n'Collar transcription factor, regulates induction of the heme oxygenase-1 gene. J. Biol. Chem. 274:26071-78.

55. Alam J, et al. (2000) Mechanism of heme oxygenase- 1 gene activation by cadmium in MCF-7 mammary epithelial cells. Role of p38 kinase and Nrf2 transcription factor. J. Biol. Chem. 275:27694-702.

56. Chorley BN, et al. (2012) Identification of novel NRF2-regulated genes by ChIP-Seq: influence on retinoid X receptor alpha. Nucleic Acids Res. 40:7416-29.

57. Walsh J, et al. (2014) Identification and quantification of the basal and inducible Nrf2-dependent proteomes in mouse liver: biochemical, pharmacological and toxicological implications. J. Proteomics. 108:171-87.

58. Shen G, et al. (2006) Modulation of nuclear factor E2-related factor 2-mediated gene expression in mice liver and small intestine by cancer chemopreventive agent curcumin. Mol. Cancer Ther. 5:39-51.

59. Ishii T, et al. (2000) Transcription factor Nrf2 coordinately regulates a group of oxidative stress-inducible genes in macrophages. J. Biol. Chem. 275:16023-29.

60. Boyle JJ, et al. (2011) Heme induces heme oxygenase 1 via Nrf2: role in the homeostatic macrophage response to intraplaque hemorrhage. Arterioscler. Thromb. Vasc. Biol. 31: 2685-91.

61. Tsuji $Y$, et al. (2000) Coordinate transcriptional and translational regulation of ferritin in response to oxidative stress. Mol. Cell. Biol. 20:5818-27.
62. Schaer DJ, Vinchi F, Ingoglia G, Tolosano E, Buehler PW. (2014) Haptoglobin, hemopexin, and related defense pathways-basic science, clinical perspectives, and drug development. Front. Physiol. 5:415.

63. Mollan TL, et al. (2014) Redox properties of human hemoglobin in complex with fractionated dimeric and polymeric human haptoglobin. Free Radic. Biol. Med. 69:265-77.

64. Balla G, Jacob HS, Eaton JW, Belcher JD, Vercellotti GM. (1991) Hemin: a possible physiological mediator of low density lipoprotein oxidation and endothelial injury. Arterioscler. Thromb. 11:1700-11.

65. Balla J, et al. (1993) Endothelial-cell heme uptake from heme proteins: induction of sensitization and desensitization to oxidant damage. Proc. Natl. Acad. Sci. U.S.A. 90:9285-89.

66. Balla J, et al. (2000) Ferriporphyrins and endothelium: a 2-edged sword-promotion of oxidation and induction of cytoprotectants. Blood. 95:3442-50.

67. Balla J, Jacob HS, Balla G, Nath K, Vercellotti GM. (1992) Endothelial cell heme oxygenase and ferritin induction by heme proteins: a possible mechanism limiting shock damage. Trans. Assoc. Am. Physicians. 105:1-6.

68. Balla J, et al. (1995) Endothelial cell heme oxygenase and ferritin induction in rat lung by hemoglobin in vivo. Am. J. Physiol. 268: L321-27.

69. Alam J, et al. (2003) Heme activates the heme oxygenase-1 gene in renal epithelial cells by stabilizing Nrf2. Am. J. Physiol. Renal Physiol. 284: F743-52.

70. Balogun E, et al. (2003) Curcumin activates the haem oxygenase-1 gene via regulation of $\mathrm{Nrf} 2$ and the antioxidant-responsive element. Biochem. J. 371:887-95.

71. Choi AM, Alam J. (1996) Heme oxygenase-1: function, regulation, and implication of a novel stress-inducible protein in oxidant-induced lung injury. Am. J. Respir. Cell Mol. Biol. 15:9-19.

72. Li N, et al. (2004) Nrf2 is a key transcription factor that regulates antioxidant defense in macrophages and epithelial cells: protecting against the proinflammatory and oxidizing effects of diesel exhaust chemicals. J. Immunol. 173:3467-81.

73. Nath KA, et al. (2000) The indispensability of heme oxygenase- 1 in protecting against acute heme protein-induced toxicity in vivo. Am. J. Pathol. 156:1527-35.

74. Thimmulappa RK, et al. (2002) Identification of Nrf2-regulated genes induced by the chemopreventive agent sulforaphane by oligonucleotide microarray. Cancer Res. 62:5196-203.

75. Dutra FF, et al. (2014) Hemolysis-induced lethality involves inflammasome activation by heme. Proc. Natl. Acad. Sci. U.S.A. 111: E4110-18.

76. Belcher JD, et al. (2016) Control of oxidative stress and inflammation in sickle cell disease with the Nrf2 activator dimethyl fumarate. Antioxid. Redox Signal. [Epub ahead of print 2016 Mar 30]. 
77. Keleku-Lukwete N, et al. (2015) Amelioration of inflammation and tissue damage in sickle cell model mice by Nrf2 activation. Proc. Natl. Acad. Sci. U.S.A. 112:12169-74.

78. Kristiansen M, et al. (2001) Identification of the haemoglobin scavenger receptor. Nature. 409:198-201.

79. Schaer DJ, Alayash AI. (2010) Clearance and control mechanisms of hemoglobin from cradle to grave. Antioxid. Redox Signal. 12:181-84.

Cite this article as: Vercellotti GM, et al. (2016) Hepatic overexpression of hemopexin inhibits inflammation and vascular stasis in murine models of sickle cell disease. Mol. Med. 22:437-51. 